\title{
Complex molecular and functional outcomes of single versus sequential cytokine stimulation of rat microglia
}

\author{
Tamjeed A. Siddiqui ${ }^{1,2}$, Starlee Lively ${ }^{1}$ and Lyanne C. Schlichter ${ }^{1,2,3^{*}}$
}

\begin{abstract}
Background: Microglia are the "professional" phagocytes of the CNS. Phagocytosis is crucial for normal CNS development and maintenance, but it can be either beneficial or detrimental after injury or disease. For instance, white matter damage releases myelin debris that must be cleared by microglia in order for re-myelination to occur. However, phagocytosis can also produce damaging reactive oxygen species (ROS). Furthermore, microglia can acquire pro-inflammatory (M1) or anti-inflammatory (M2) activation states that affect cell functions. Although microglia are exposed to a changing cytokine environment after injury or disease, little is known about the molecular and functional consequences. Therefore, we applied several microglial activation paradigms, with or without myelin debris. We assessed (i) gene expression changes reflecting microglial activation and inflammatory states, and receptors and enzymes related to phagocytosis and ROS production, (ii) myelin phagocytosis and production of ROS, and (iii) expression and contributions of several ion channels that are considered potential targets for regulating microglial behavior.
\end{abstract}

Methods: Primary rat microglia were exposed to cytokines, individually or sequentially. First, responses to individual M1 or M2 stimuli were compared: IFN- $\gamma$ plus TNF-a ("I + T"; M1 activation), interleukin-4 (M2a/alternative activation), and interleukin-10 (M2c/acquired deactivation). Second, sequential cytokine addition was used to assess microglia repolarization and cell functions. The paradigms were $\mathrm{M} 2 \mathrm{a} \rightarrow \mathrm{M} 1, \mathrm{M} 2 \mathrm{C} \rightarrow \mathrm{M} 1, \mathrm{M} 1 \rightarrow \mathrm{M} 2 \mathrm{a}$, and $\mathrm{M} 1 \rightarrow \mathrm{M} 2 \mathrm{c}$.

Results: M1 stimulation increased pro-inflammatory genes, phagocytosis, and ROS, as well as expression of Kv1.3, KCa3.1, and Kir2.1 channels. M2a stimulation increased anti-inflammatory genes, ROS production, and Kv1.3 and KCa3.1 expression. Myelin phagocytosis enhanced the M1 profile and dampened the M2a profile, and both phagocytosis and ROS production were dependent on NOX enzymes and Kir2.1 and CRAC channels. Importantly, microglia showed some capacity for re-polarization between M1 and M2a states, based on gene expression changes, myelin phagocytosis, and ROS production.

Conclusions: In response to polarizing and re-polarizing cytokine treatments, microglia display complex changes in gene transcription profiles, phagocytic capacity, NOX-mediated ROS production, and in ion channels involved in microglial activation. Because these changes might affect microglia-mediated CNS inflammation, they should be considered in future experimental, pre-clinical studies.

Keywords: Neuroinflammation, CNS phagocytes, Microglia molecular polarization, Microglial activation states, M1, M2a, M2C activation, Myelin phagocytosis, Phagocytosis receptor expression, $\mathrm{K}^{+}$channels, $\mathrm{Ca}^{2+}$ channels, ROS production

\footnotetext{
* Correspondence: schlicht@uhnres.utoronto.ca

${ }^{1}$ Genes and Development Division, Krembil Research Institute, University Health Network, Toronto, Ontario M5T 258, Canada

${ }^{2}$ Department of Physiology, University of Toronto, Toronto, Ontario, Canada

Full list of author information is available at the end of the article
} 


\section{Background}

Phagocytosis is crucial during central nervous system (CNS) development and in the healthy adult to both promote and maintain appropriate synaptic connections and homeostasis. After CNS injury or disease, phagocytosis is crucial for clearing cellular debris, including degenerated myelin after acute injury or degenerative diseases, such as multiple sclerosis. For CNS repair to occur, myelin debris must be rapidly removed because it inhibits differentiation of oligodendrocyte precursor cells and re-myelination, and promotes formation of membrane attack complexes that further damage myelin [1-3]. Microglia are the "professional" phagocytes of the CNS. However, phagocytosis can have both beneficial and detrimental effects (reviewed in [3-9]). Microglia can exacerbate damage by producing excessive reactive oxygen species (ROS) during phagocytosis [10-12]. This ROS production, which is mediated by nicotinamide adenine dinucleotide phosphate (NADPH) oxidases (NOX enzymes), can contribute to DNA damage, lipid peroxidation, toxic protein alterations, and neurotoxicity [13-16].

In considering both harmful and helpful outcomes of phagocytosis, it is important to note that microglia can adopt several activation states or possibly a continuum of states (reviewed in [17-20]). It is generally thought that the pro-inflammatory (M1) state exacerbates tissue damage and that anti-inflammatory (M2) states help in tissue repair; however, very few studies have compared phagocytosis and ROS production in different activation states. Experimentally, M1 activation is usually evoked by lipopolysaccharide (LPS), with or without the proinflammatory cytokine, interferon gamma (IFN- $\gamma$ ). M2a (alternative) activation is evoked by interleukin-4 (with or without interleukin (IL)-13). M2c (acquired deactivation) is usually evoked by IL-10 (less often by glucocorticoid hormones). However, some suggest that IL-10 evokes gene changes more closely resembling an M1 profile [21]. Further complexity in microglial activation in vivo arises from dynamic changes in the CNS environment over time after injury or disease.

In vitro studies have addressed the microglial phagocytic capacity for plastic beads, bacteria, apoptotic cells, red blood cells, and less often, myelin. Little is known about the relationship between microglial activation states, myelin phagocytosis and ROS production, and, conversely, how myelin phagocytosis affects microglial activation states. The limited studies report that M1 activation of rat microglia increases phagocytosis of myelin (LPS or IFN- $\gamma$ stimulation) [22]. Results on M2activated microglia are inconsistent. M2a activation with IL-4 and/or IL-13 increased myelin phagocytosis by human microglia [23] but not rat microglia [22]. M2c activation of rat microglia with IL-10 increased myelin phagocytosis [22]. It is not known how sequentially exposing microglia to M1- versus M2-inducing cytokines affects their activation state, phagocytic capacity, or ROS production.

We began by comparing unstimulated, M1- and M2activated rat microglia, quantifying myelin phagocytosis, ROS production, and expression of inflammatory mediators and receptors/enzymes related to phagocytosis and ROS production. Then, we examined how all these responses were affected by applying an M1 stimulus followed by an M2 stimulus and vice versa. Finally, under all the activation paradigms, we assessed expression and contributions of several ion channels that are known to regulate other functions of rat microglia: $\mathrm{KCa} 3.1, \mathrm{Kv} 1.3$, Kir2.1, as well as Orai and stromal interaction molecule (STIM) subunits that form store-operated and $\mathrm{Ca}^{2+}$ release-activated $\mathrm{Ca}^{2+}$ (CRAC) channels.

\section{Methods}

\section{Primary cultures of rat microglia and activation states}

Handling and sacrifice of rat pups was in accordance with guidelines from the Canadian Council on Animal Care and approved by the University Health Network Animal Care Committee (Animal Use Permit \#914). Pure microglial cultures were prepared from 1-2-day-old SpragueDawley rat pups (Charles River, St. Constant, PQ, Canada), as before [24-27]. In brief, the meninges and cerebellum were removed from the excised brain, and the remaining tissue was mashed in cold minimal essential medium (MEM; Invitrogen, Carlsbad, CA), strained, and centrifuged at $300 \times g$ for $10 \mathrm{~min}$. After re-suspending in MEM, cells were seeded in MEM that contained $10 \%$ heatinactivated fetal bovine serum (FBS; Wisent St. Bruno, $\mathrm{PQ}$, Canada) and $0.05 \mathrm{mg} / \mathrm{mL}$ gentamycin (Invitrogen). The cells were incubated at $37{ }^{\circ} \mathrm{C}$ with $5 \% \mathrm{CO}_{2}$ for $48 \mathrm{~h}$, and then, the medium was changed to remove cellular debris and non-adherent cells. After 5-6 days, microglia were harvested by shaking the flasks for 3-4 h on an orbital shaker at $70 \mathrm{rpm}\left(37{ }^{\circ} \mathrm{C}, 5 \% \mathrm{CO}_{2}\right)$. The supernatant that contained microglia was collected and centrifuged (300×g, $10 \mathrm{~min}$ ), and the pellet was re-suspended in fresh MEM with $2 \%$ heat-inactivated FBS and $0.05 \mathrm{mg} / \mathrm{mL}$ gentamycin. Microglia were seeded onto 96-well tissue culture plates at $7-8 \times 10^{4}$ cells/well (for phagocytosis and ROS assays), 7-8 $\times 10^{4}$ cells $/ 15 \mathrm{~mm}$ coverslip (for fluorescence microscopy), and $>10^{5}$ cells/coverslip (for mRNA collection).

To induce different activation states, microglia were exposed to recombinant rat cytokines (R\&D Systems Inc., Minneapolis, MN). A classical (M1) state was induced by $20 \mathrm{ng} / \mathrm{mL}$ IFN- $\gamma$ plus $50 \mathrm{ng} / \mathrm{mL}$ TNF- $\alpha$ (for $24 \mathrm{~h}$ ): a treatment we refer to as " $\mathrm{I}+\mathrm{T}$ ". Alternative activation (M2a) was induced by $20 \mathrm{ng} / \mathrm{mL}$ IL-4 (for $24 \mathrm{~h}$ ). Acquired deactivation (M2c) was induced with $20 \mathrm{ng} / \mathrm{mL}$ IL-10 (for $24 \mathrm{~h}$ ). Stock solutions were made in sterile PBS with $0.3 \%$ 
bovine serum albumin and stored at $-20{ }^{\circ} \mathrm{C}$. For sequential cytokine additions, the first treatment (IL-4 or I $+\mathrm{T}$ ) was applied for $2 \mathrm{~h}$, and then, the second (IL-4, I + T, IL-10) was added for an additional $22 \mathrm{~h}$ without washing.

\section{nCounter gene expression assay (NanoString)}

This multiplexed assay quantifies expression of multiple, investigator-selected genes in a single ribonucleic acid (RNA) sample, with sensitivity comparable to real-time quantitative RT-PCR [28]. We collected samples from separate microglia cultures $(n=6)$ and extracted total RNA using TRIzol reagent (Invitrogen) and the RNeasy Mini Kit (QIAGEN, Mississauga, ON, Canada), as previously described $[24,25,29]$. RNA samples were stored at $-80^{\circ} \mathrm{C}$. Then, $200 \mathrm{ng}$ of extracted RNA from each separate sample was sent for analysis to the Princess Margaret Genomics Centre (www.pmgenomics.ca; Toronto, Canada). A custom CodeSet (Table 1) was designed by NanoString Technologies (Seattle, WA) for genes we had selected based on previously reported changes with M1 and M2 activation states, their role in phagocytosis or ROS production, and the channels being investigated in this study. RNA integrity was assessed using Nanodrop 1000, and then, the nCounter Gene Expression Assay (sample hybridization, detection, scanning) was conducted according to NanoString Technologies' recommendations. Data were normalized to the geometric mean expression of three housekeeping genes: hypoxanthine guanine phosphoribosyl transferase 1 (HPRT1), $\beta$-glucuronidase (GusB), and 60S ribosomal protein L32 (Rpl32). Reporter probe counts, which reflect the numbers of a particular mRNA transcript in the 200 ng RNA sample, were analyzed and quantified using the nCounterTM digital analyzer software2.

\section{Myelin phagocytosis and ROS production}

Myelin was isolated by homogenizing adult rat brains (weighing 1.95-2.10 g) in iso-osmotic buffer, followed by sucrose gradient centrifugation [30]. The myelin concentration was calculated from the total protein concentration, using the Pierce bicinchoninic acid (BCA) assay (Thermo Fisher Scientific, Waltham, MA), and adjusted as required. Myelin was labeled in the dark with the lipophilic dye, 1,1' -dioctadecyl-3,3,3',3'-tetramethylindocarbocyanine perchlorate (DiI) (Molecular Probes, Burlington, ON, Canada) $\left(1: 200 ; \geq 2 \mathrm{~min}, 37^{\circ} \mathrm{C}\right)$, as is commonly done for phagocytosis studies [10, 31]. Microglia were seeded at $7-8 \times 10^{4}$ cells per $15-\mathrm{mm}$ glass coverslip. They were cultured for 1-2 days without complement proteins [32] by using $2 \%$ heat-inactivated FBS at $37{ }^{\circ} \mathrm{C}, 5 \% \mathrm{CO}_{2}$, and then incubated with DiIlabeled myelin. Extracellular myelin was removed by washing with standard bath solution (for phagocytosis and ROS assays), Trizol reagent (for RNA isolation) or fixative (for fluorescence microscopy). The cells were plated at the same high density, and the plate reader was configured to measure fluorescence intensity at the bottom of the plate. At the end of every experiment, we monitored the cell health and saw no evidence of damage, death, or obvious differences in cell numbers.

Myelin phagocytosis was first optimized by incubating microglia with 5,25 , or $50 \mu \mathrm{g} / \mathrm{mL}$ myelin for $6 \mathrm{~h}$ or with $25 \mu \mathrm{g} / \mathrm{mL}$ myelin for 1,3 , or $6 \mathrm{~h}$. Phagocytosis of DiI-labeled myelin fragments was verified by fluorescence microscopy in microglia that were fixed in $4 \%$ paraformaldehyde (10 $\mathrm{min}$, room temperature) and stained with FITC-conjugated tomato lectin (1:500, 15 min; Sigma-Aldrich, Oakville, ON) and the nuclear stain, 4',6-diamidino-2-phenylindole (DAPI; 1:3000, $5 \mathrm{~min}$; Cayman Chemical, Ann Arbor, Michigan). After washing (three times, $5 \mathrm{~min}$ ), cells on coverslips were mounted on glass slides with Dako mounting medium (Dako, Glostrup, Denmark) and stored in the dark at $4{ }^{\circ} \mathrm{C}$ until images were acquired with an Axioplan 2 wide-field epifluorescence microscope equipped with an Axiocam HR digital camera (both from Zeiss, Toronto, ON, Canada).

An earlier study of murine microglia showed that myelin debris was internalized within $1 \mathrm{~h}$ and accumulated in LAMP-1-positive lysosomes, presumably targeted for degradation [10]. We verified that unstimulated (control) rat microglia rapidly phagocytose myelin fragments under the present conditions. At $25 \mu \mathrm{g} / \mathrm{mL}$ myelin, uptake was substantial by $3 \mathrm{~h}$, and by $6 \mathrm{~h}$, DiI-labeled myelin fragments had accumulated mainly in the perinuclear region, with a small amount in other cell regions (Fig. 1a). For the remaining study, we chose a 6-h incubation with $25 \mu \mathrm{g} /$ $\mathrm{mL}$ myelin. The washing procedure effectively removed extracellular myelin debris (Fig. 1a); thus, we could use a multi-label fluorescence plate reader to quantify myelin phagocytosis.

To quantify ROS, microglia were incubated $\left(1 \mathrm{~h}, 37^{\circ} \mathrm{C}\right.$, $5 \% \mathrm{CO}_{2}$ ) with the membrane-permeant probe, a chloromethyl derivative of $2^{\prime}, 7^{\prime}$-dichlorodihydrofluorescein diacetate $\left(\mathrm{CM}-\mathrm{H}_{2} \mathrm{DCFDA} ; 5 \mu \mathrm{M}\right.$; Invitrogen). The probe is cleaved by intracellular esterases to release $\mathrm{H}_{2}$ DCFDA, which is then oxidized to a fluorescent compound, dichlorodihydrofluorescein (DCF) that remains trapped in the cells. DCF (495 nm excitation, $525 \mathrm{~nm}$ emission) is a general ROS probe that is compatible with DiI-labeled myelin (553 nm excitation, $570 \mathrm{~nm}$ emission), thus allowing myelin phagocytosis and ROS production to be monitored in the same samples. Extracellular CM- $\mathrm{H}_{2}$ DCFDA and myelin fragments were removed by washing the coverslips with standard bath solution, which contained (in mM) $125 \mathrm{NaCl}, 5 \mathrm{KCl}, 1 \mathrm{CaCl}_{2}, 1 \mathrm{MgCl}_{2}, 10$ HEPES, and 5 D-glucose ( $\mathrm{pH} 7.4 ; 290-300 \mathrm{mOsm})$. As a positive control for ROS production, microglia were occasionally stimulated for $1 \mathrm{~h}$ with the PKC activator, 
Table 1 Target sequences used to design custom CodeSet for nCounter assay

\begin{tabular}{|c|c|c|}
\hline Gene & Gene accession \# & Target sequence \\
\hline Aif1 (Iba1) & NM_017196.2 & $\begin{array}{l}\text { ATCGATATTATGTCCTTGAAGCGAATGCTGGAGAAACTTGGGGTTCCCAAGACCCATCTAGAGCTGAAGAAATTAATTAGA } \\
\text { GAGGTGTCCAGTGGCTCCG }\end{array}$ \\
\hline $\mathrm{Ccl} 22$ & NM_057203.1 & $\begin{array}{l}\text { TACATCCGTCACCCTCTGCCACCACGTTTCGTGAAGGAGTTCTACTGGACCTCAAAGTCCTGCCGCAAGCCTGGCGTCGTTT } \\
\text { TGATAACCATCAAGAACC }\end{array}$ \\
\hline Cd11b (Itgam) & NM_012711.1 & $\begin{array}{l}\text { CATCCCTTCCTTCAACAGTAAAGAAATATTCAACGTCACCCTCCAGGGCAATCTGCTATTTGACTGGTACATCGAGACTTCTC } \\
\text { ATGACCACCTCCTGCTT }\end{array}$ \\
\hline Cd68 (ED1) & NM_001031638.1 & $\begin{array}{l}\text { CTCTCATTCCCTTACGGACAGCTTACCTTTGGATTCAAACAGGACCGACATCAGAGCCACAGTACAGTCTACC } \\
\text { TTAACTACATGGCAGTGGAATACAATG }\end{array}$ \\
\hline Cd163 & NM_001107887.1 & $\begin{array}{l}\text { CCTCTGTAATTTGCTCAGGAAACCAATCGCATACACTGTTGCCATGTAGTTCATCATCTTCGGTCCAAACAACA } \\
\text { AGTTCTACCATTGCAAAGGACAGTGA }\end{array}$ \\
\hline $\mathrm{C} 1 \mathrm{r}$ & XM_001061611.1 & $\begin{array}{l}\text { ACAAAGACCTTATGGGTTATGTCAGCGGCTTCGGGATAACAGAAGATAAAATAGCTTTIAATCTCAGGTTTGTC } \\
\text { CGTCTGCCCATAGCCGATCGAGAGGC }\end{array}$ \\
\hline Cybb (Nox2) & NM_023965.1 & $\begin{array}{l}\text { CAGTACCAAAGTTGGCCGGAAACCCTCCTATGACTTGGAAATGGATCGTGGGTCCCATGTTCCTGTATCTGTGT } \\
\text { GAGAGGCTGGTGCGGTITGGCGATC }\end{array}$ \\
\hline Ptgs2 (COX-2) & NM_017232.3 & $\begin{array}{l}\text { TTCGGAGGAGAAGTGGGTTTIAGGATCATCAACACTGCCTCAATTCAGTCTCTCATCTGCAATAATGTGAAAGG } \\
\text { GTGTCCCTITGCCTCTITCAATGTGC }\end{array}$ \\
\hline $\mathrm{C} \times 3 \mathrm{Cr} 1$ & NM_133534.1 & $\begin{array}{l}\text { ATGTGCAAGCTCACGACTGCTTTCTTCTTCATTGGCTTCTTTGGGGGCATATTCTTCATCACCGTCATCAGCATCG } \\
\text { ACCGGTACCTCGCCATCGTCCTGG }\end{array}$ \\
\hline FcyR1a & NM_001100836.1 & $\begin{array}{l}\text { TGATGGATCATACTGGTGCGAGGTAGCCACGGAGGACGGCCGTGTCCTTAAGCGCAGCACCAAGTTGGAGCT } \\
\text { ATTGGTCCCCAGTCATCAGATCCTGTC }\end{array}$ \\
\hline FcyR2b & NM_175756.1 & $\begin{array}{l}\text { CTGGTCCAAGGAATGCTGTAGATATGAAAGAAAACATCTAGAGTCCCTTCTGTGAGTCCTGAAACCAACAGACAC } \\
\text { TACGATATTGGTTCCCAATGGTTGA }\end{array}$ \\
\hline FcyR3a & NM_207603.1 & $\begin{array}{l}\text { GACTCTTGTTGCAATAGACACAGTGCTGTATTTCTCGGTGCAGAGGAGTCTTCAAAGTTCCGTGGCAGTCTATGA } \\
\text { GGAACCCAAACTTCACTGGAGCAA }\end{array}$ \\
\hline Gusb & NM_017015.2 & $\begin{array}{l}\text { TCATTTGATCCTGGATGAGAAACGAAAAGAATATGTCATCGGAGAGCTCATCTGGAATTTTGCTGACTTCATGACG } \\
\text { AACCAGTCACCACTGAGAGTAACA }\end{array}$ \\
\hline Havcr2 (TIM-3) & NM_001100762.1 & $\begin{array}{l}\text { CGATGAAATTAAGGACTCTGGAGAAACTATCAGAACTGCTGTCCACATTGGAGTAGGCGTCTCTGCTGGGCTGGC } \\
\text { CCTGGCACTTATTCTTGGTGTTITA }\end{array}$ \\
\hline Hprt1 & NM_012583.2 & $\begin{array}{l}\text { AGCTTCCTCCTCAGACCGCTITTCCCGCGAGCCGACCGGTTCTGTCATGTCGACCCTCAGTCCCAGCGTCGTGATT } \\
\text { AGTGATGATGAACCAGGTTATGAC }\end{array}$ \\
\hline Hven1 (Hv1) & XM_006249369.2 & $\begin{array}{l}\text { ACCAAGAGGATGAGCAGGTTCTTGAAGCACTTCACAGTGGTGGGGGACGACTACCACACCTGGAATGTCAACTA } \\
\text { CAAGAAGTGGGAGAACGAGGAGGATG }\end{array}$ \\
\hline 116 & NM_012589.1 & $\begin{array}{l}\text { GGAACAGCTATGAAGTTCTCTCCGCAAGAGACTTCCAGCCAGTTGCCTTCTTGGGACTGATGTTGTTGACAGCCA } \\
\text { CTGCCTTCCCTACTTCACAAGTCC }\end{array}$ \\
\hline Kcna3 (Kv1.3) & NM_019270.3 & $\begin{array}{l}\text { GCCACCTTCTCCAGAAATATCATGAACCTGATAGACATTGTAGCCATCATCCCTTATTTTATTACTCTGGGCACTGAG } \\
\text { CTGGCTGAGCGACAGGGTAATG }\end{array}$ \\
\hline Kcnj2 (Kir2.1) & NM_017296.1 & $\begin{array}{l}\text { GTTCTITGGCTGTGTGTITGGTTGATAGCTCTGCTCCACGGGGATCTGGATGCTTCTAAAGAGAGCAAAGCGTGTGTG } \\
\text { TCTGAGGTCAACAGCTTCACG }\end{array}$ \\
\hline Kcnn4 (KCa3.1) & NM_023021.2 & $\begin{array}{l}\text { TACGTCTCTACCTGGTGCCTCGCGCGGTACTTCTGCGTAGCGGGGTCCTGCTCAACGCGTCTTACCGCAGCATCGGGG } \\
\text { CGCTCAACCAAGTCCGATTCCG }\end{array}$ \\
\hline Mrc1 & NM_001106123.1 & $\begin{array}{l}\text { CTITGGAATCAAGGGCACAGAGCTATATTTAACTATGGCAACAGGCAAGAAAAGAATATCAAGCTTIACAAAGGTTC } \\
\text { CGGTTTGTGGAGCAGATGGAAG }\end{array}$ \\
\hline Msr1 (SR-A) & NM_001191939.1 & $\begin{array}{l}\text { CACGTTCCATGACAGCATCCCTTCCTCACAACACTATAAATGGCTCCTCCGTTCAGGAGAAACTGAAGTCCTTCAAAGT } \\
\text { TGCCCTCGTCGCTCTCTACCT }\end{array}$ \\
\hline Myc & NM_012603.2 & $\begin{array}{l}\text { ACCGAGGAAAACGACAAGAGGCGGACACACAACGTCTTGGAACGTCAGAGGAGAAACGAGCTGAAGCGTAGCTITाT } \\
\text { TGCCCTGCGCGACCAGATCCCTG }\end{array}$ \\
\hline Ncf1 & NM_053734.2 & $\begin{array}{l}\text { TCCATTCCCAGCATCCCATAATTGGGCTTGTCCGTGTTCCAACATCTGGGCGGAATTTCACAGCCAAAGGTCAAGAGGA } \\
\text { CTGCTGTTACGTTCAAGGTCG }\end{array}$ \\
\hline Nos2 (iNOS) & NM_012611.2 & $\begin{array}{l}\text { ACGGGACACAGTGTCGCTGGTTTGAAACTTCTCAGCCACCTTGGTGAGGGGACTGGACTTTAAGAGACGCTTCTGAGG } \\
\text { TTCCTCAGGCTTGGGTCTTGTT }\end{array}$ \\
\hline Nox1 & NM_053683.1 & $\begin{array}{l}\text { CCGAGAAAGAAGATTCTTGGCTAAATCCCATCCAGTCTCCAAACGTGACAGTGATGTATGCAGCATTTACCAGTATTGC } \\
\text { TGGCCTTACTGGAGTGGTCGC }\end{array}$ \\
\hline Nox4 & NM_053524.1 & $\begin{array}{l}\text { TGTTGGACAAAAGCAAGACTCTACATATCACCTGTGGCATAACTATTTGTATTTTCTCAGGTGTGCATGTAGCTGCCCAC } \\
\text { TTGGTGAACGCCCTGAACTT }\end{array}$ \\
\hline
\end{tabular}


Table 1 Target sequences used to design custom CodeSet for nCounter assay (Continued)

\begin{tabular}{|c|c|c|}
\hline P2ry6 & NM_057124.2 & $\begin{array}{l}\text { TGGCCCAACATGCCTGGCCCTCCAAAATTTCTATGTCAACCACAAAACTAAGACACCTGTGTTTCGGGGACTGGTCAGT } \\
\text { TCATGCTTGTTATACCAGAAT }\end{array}$ \\
\hline Orai1 & NM_001013982.1 & $\begin{array}{l}\text { GCCTTCTCCACCGTCATCGGGACGCTGCTTITCCTGGCCGAAGTCGTGCTGCTCTGCTGGGTGAAGTTCTTACCGCTCAA } \\
\text { GAGGCAGGCGGGACAGCCAA }\end{array}$ \\
\hline Orai3 & NM_001014024.1 & $\begin{array}{l}\text { ACCTGTAATGTGCTTTACAGTTGGCATCCTGGGAGAGATTTTACATAGGCTCCTCAGATGAACCACTTTACACTTGGTGA } \\
\text { CTTGTGGTGGTGTGTCCCAC }\end{array}$ \\
\hline Rpl32 & NM_013226.2 & $\begin{array}{l}\text { CATCGTAGAAAGAGCAGCACAGCTGGCCATCAGAGTCACCAATCCCAACGCCAGGCTACGCAGCGAAGAGAATGAAT } \\
\text { AGATGGCTTGTGTGCCTGTITTG }\end{array}$ \\
\hline Sirpa & NM_013016.2 & $\begin{array}{l}\text { AGGACATTCATTCTCGGGTCATCTGCGAGGTAGCCCACGTCACCTTGGAAGGACGCCCGCTTAATGGGACCGCTAACTT } \\
\text { TTCTAACATCATCCGAGTITC }\end{array}$ \\
\hline Stim1 & NM_001108496.2 & $\begin{array}{l}\text { TATCTATCGTGATTGGTGTGGGTGGCTGCTGGTTTGCCTATATCCAGAACCGTTACTCTAAGGAGCACATGAAGAAAATG } \\
\text { ATGAAGGATCTGGAAGGATT }\end{array}$ \\
\hline Stim2 & NM_001105750.2 & $\begin{array}{l}\text { TTCACAATTGGACGCTTGAGGATACCCTGCAGTGGTTGATAGAATTTGTGAACTCCCACAATACGAGAAGAATTTAAGGG } \\
\text { ATAATAATGTGAAAGGAAC }\end{array}$ \\
\hline Tnfa & NM_012675.2 & $\begin{array}{l}\text { GGTGATCGGTCCCAACAAGGAGGAGAAGTTCCCAAATGGGCTCCCTCTCATCAGTTCCATGGCCCAGACCCTCACACTCA } \\
\text { GATCATCTTCTCAAAACTCG }\end{array}$ \\
\hline Trem2 & NM_001106884.1 & $\begin{array}{l}\text { TCCGGCTGGCTGAGGAAGGGTGCCATGGAACCTCTCCACGTGTTTGTCCTGTTGCTGGTCACAGAGCTGTCCCAAGCCCTC } \\
\text { AACACCACAGTGCTGCAGG }\end{array}$ \\
\hline
\end{tabular}

phorbol 12-myristate 13-acetate (PMA; 100 nM, Sigma), which produced a robust DCF signal (not shown).

To assess contributions of the ion channels, we used well-known blockers at concentrations that we previously validated are sufficient to block the channels in primary rat microglia. As before, there was no toxicity at the concentrations used. $\mathrm{KCa} 3.1$ (also known as IK1, SK4) was blocked with 1-[(2-chlorophenyl) diphenylmethyl]-1H-pyrazole (TRAM-34; 1 $\mu \mathrm{M}$; Sigma) as before $[24,27,33,34]$. Kir2.1 was blocked with $N$-[(4-methoxyphenyl)methyl]-1-naphthalene-methanamine hydrochloride (ML133; $20 \mu \mathrm{M}$; Tocris Bioscience, MO) as in our recent study [35]. Kv1.3 was blocked with 5-nM agitoxin-2 (Sigma) as before [36-38]. CRAC channels were blocked with $N$-[4[3,5-bis(trifluoromethyl)-1H-pyrazol-1-yl]phenyl]-4-methyl1,2,3-thiadiazole-5-carboxamide (BTP2; $10 \mu \mathrm{M}$; EMD Millipore, San Diego, CA). We previously showed that $10 \mu \mathrm{M}$ BTP2 blocks $\mathrm{Ca}^{2+}$ signaling through CRAC $[33,35]$. Stock solutions were made in sterile double distilled water (agitoxin-2) or DMSO (TRAM-34, ML133, BTP2) and stored at $-20{ }^{\circ} \mathrm{C}$. When used, the channel blockers were applied together with myelin.

\section{Statistical analysis}

All graphical data are presented as mean \pm standard error of the mean (SEM) for the $n$ values indicated. The statistical significance of results was analyzed with a one- or two-way analysis of variance (ANOVA) and post hoc analysis as indicated in the figure legends. Results were considered significant if $p<0.05$

\section{Results \\ Myelin phagocytosis affects the activation state of primary rat microglia}

When unstimulated (control) microglia were exposed to $25 \mu \mathrm{g} / \mathrm{mL}$ of myelin debris for $6 \mathrm{~h}$, myelin was seen mainly in the perinuclear region, with a small amount in other cell regions (Fig. 1a). We then examined expression of over two dozen genes to create a profile of microglial responses to the activating stimuli and to myelin debris. Previously, by assessing several wellknown inflammatory genes, we found that unstimulated rat microglia were in a relatively resting state $[25,29,39]$. This was confirmed, based on very low expression of wellestablished pro-inflammatory (M1) molecules (NOS2/ iNOS, TNF- $\alpha$, COX-2, IL-6), and of some markers of 'alternative' (M2) activation (cluster of differentiation (CD)163, CCL22). Two M2-associated molecules, c-myc and MRC1, were expressed at moderate levels, and MRC1 expression was similar to our recent study [24]. When unstimulated cells were allowed to phagocytose myelin for $6 \mathrm{~h}$, none of these markers changed significantly (Fig. 1b).

The same inflammatory markers were quantified after microglia were treated with cytokines to evoke two different activation states, and again, after myelin phagocytosis (Fig. 1b, c). Previously validated M1 markers included increased NOS2, COX-2, IL-6, and a loss of M2a markers [21]. Here, classical (M1) activation was evoked by $24 \mathrm{~h}$ treatment with a combination of IFN- $\gamma$ and TNF- $\alpha$ (which we call " $\mathrm{I}+\mathrm{T}$ "). As expected, there was a dramatic increase in expression of pro-inflammatory molecules (NOS2, TNF- $\alpha$, COX-2); IL-6 increased to a lesser degree. Conversely, IL-4 (M2a, alternative activation) increased expression of several M2-associated molecules (MRC1, 

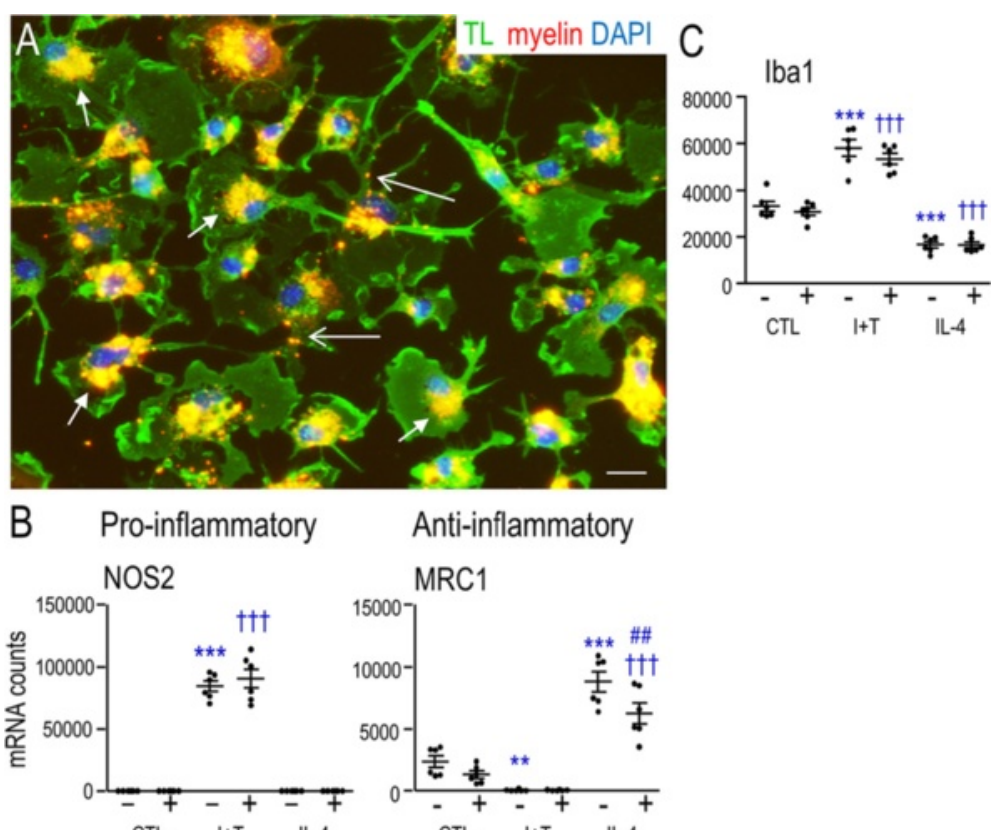

Anti-inflammatory
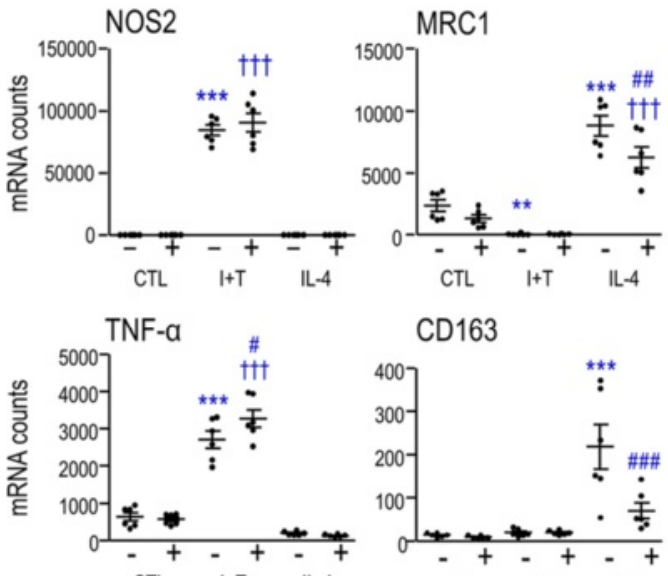

CD163
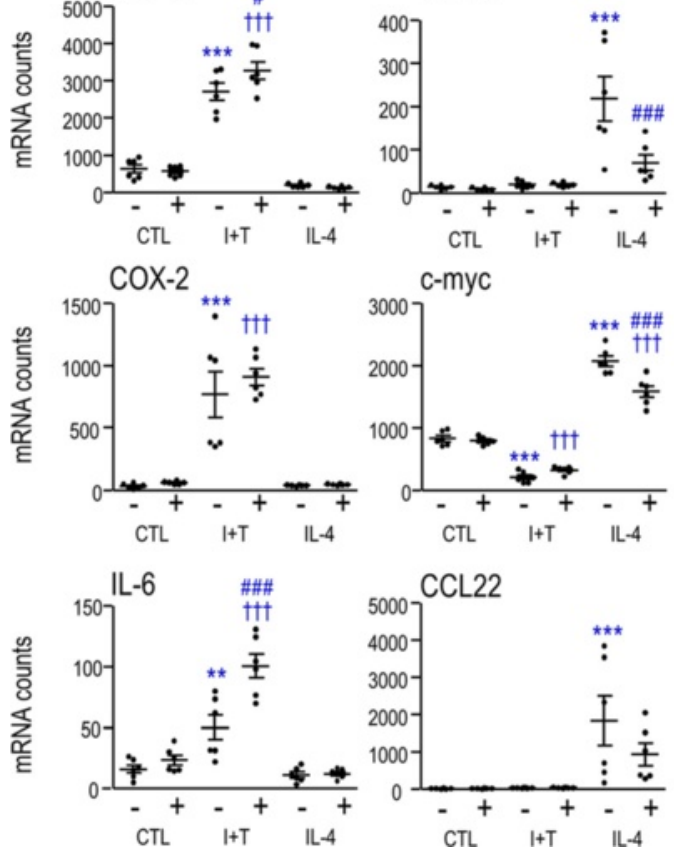

Fig. 1 Effects of microglial activation state and exposure to myelin on inflammatory gene expression. a Myelin phagocytosis. Representative images showing myelin fragments inside primary rat microglia at $6 \mathrm{~h}$ after adding $25 \mu \mathrm{g} / \mathrm{mL}$ Dil-labeled myelin (red). Microglia were co-labeled with tomato lectin ( $T L$, green) and the nuclear stain, DAPI (blue). Scale bar, $10 \mu \mathrm{m}$. Short arrows show peri-nuclear accumulation of myelin; long arrows show myelin in other cell regions. b, c Gene expression of inflammatory markers (b) and "ionized Ca ${ }^{2+}$ binding adapter molecule 1" (c lba1; also known as AIF-1). Microglia were unstimulated (control, CTL) or stimulated for $24 \mathrm{~h}$ with $20 \mathrm{ng} / \mathrm{mL} \mathrm{IFN}-\mathrm{\gamma}$ and $50 \mathrm{ng} / \mathrm{mL}$ TNF-a (I + T) or $20 \mathrm{ng} / \mathrm{mL} I \mathrm{~L}-4$, with or without a subsequent 6-h exposure to $25 \mathrm{\mu g} / \mathrm{mL}$ myelin (30 h total time after cytokine addition; plus or minus sign indicates presence/absence of myelin). Expression of each gene is shown as normalized mRNA counts (described in the "Methods" section). On the scatterplots, the mean \pm SEM is indicated for six different microglia cultures. Data were analyzed by two-way ANOVA with Bonferroni's post hoc test. The comparisons are as follows. Asterisk Between unstimulated microglia $(C T L)$ and cells treated with I + T or IL-4. Dagger sign CTL versus activated cells in the presence of myelin. Number sign Effects of myelin within a particular activation state. One symbol $p<0.05$, two symbols $p<0.01$, three symbols $p<0.001$ 
CD163, c-myc, CCL22). Interestingly, while Iba1 expression increased in the M1 state and decreased in the M2 state, it was robustly expressed under all conditions (Fig. 1c) and is thus not strictly an activation marker.

Microglia were treated with cytokines (as above), exposed to myelin for a further $6 \mathrm{~h}$, and gene expression was again quantified. After myelin phagocytosis, M1-polarized microglia showed increased expression of some pro-inflammatory molecules (TNF- $\alpha$, IL-6). In M2a-polarized microglia, phagocytosis decreased several genes associated with alternative activation (MRC1, CD163, c-myc). Overall, these results suggest that myelin can rapidly exacerbate some proinflammatory responses of M1-polarized microglia and reduce $\mathrm{M} 2 \mathrm{a}$ polarization.

\section{The microglial activation state affects myelin phagocytosis and expression of phagocytosis-related molecules}

It is very difficult to quantify phagocytosis in vivo; thus, many studies use surrogate phagocytosis "markers" such as the glycoprotein, CD68 (ED1) [3]. Here, we compared expression of a panel of phagocytosis-related molecules in untreated, M1- and M2a-activated microglia (Fig. 2a). The molecules were chosen for the following reasons. To phagocytose myelin in vitro, microglia primarily use the scavenger class A receptor (SR-A), complement receptor 3 (CR3) (also called $\alpha_{\mathrm{M}} \beta_{2}$ and comprised of CD11b and CD18), and immunoglobulin Fc gamma receptors (if antimyelin antibodies are present) [2, 3, 40]. We quantified expression of SR-A, Fc $\gamma$ RIa, FcyRIIb, Fc $\gamma$ RIIIa, and CD11b. FcyRIa (CD64) and FcyRIIIa (CD16) stimulate phagocytosis; whereas, FcyRIIb (CD32) is inhibitory [41], as is signal regulatory protein alpha $(\mathrm{SIRP} \alpha)(\mathrm{CD} 172 \mathrm{a})$, which interacts with CD47 ligand on myelin [1]. CD68 and CR3 are often used as general markers of microglial activation because their staining intensity increases after CNS injury [7, 42-44]. $\mathrm{C} 1 \mathrm{r}$ is an essential protease that initiates the classical complement pathway to opsonize particles with complement proteins for targeted phagocytosis [45]. Nucleotides released by damaged cells act as "find-me" signals for phagocytes, and UDP acts on metabotropic $\mathrm{P}_{2} \mathrm{Y}_{6}$ receptors to facilitate phagocytosis. This receptor is up-regulated in microglia in response to dying neurons $[7,46]$. Recently, triggering receptor expressed on myeloid cells 2 (TREM2), $\mathrm{CX}_{3} \mathrm{CR} 1$, and T-cell immunoglobulin and mucin-domain containing 3 (TIM-3) have been added to the list of receptors involved in microglial phagocytosis. TREM2 senses lipid components of damaged myelin, is required for debris clearance, and is mainly expressed on microglia [47]. In the $\mathrm{CNS}, \mathrm{CX}_{3} \mathrm{CR} 1$ is expressed exclusively by microglia and perivascular macrophages [48] and is required for effective clearance of myelin debris [49]. TIM-3 is present in human microglia that are specifically localized to white matter [50]. LPS increases TIM-3 expression in murine microglia, and blocking its activity decreases their phagocytosis of apoptotic neurons [51].

(i) In untreated microglia, there was substantial expression (arbitrary cutoff, $>5000$ mRNA counts/ $200 \mathrm{ng}$ RNA) of several stimulatory receptors (CD11b, SR-A, Fc $\gamma$ RIa, Fc $\gamma$ RIIIa, CD68, TREM2) and the inhibitory receptors, Fc $\gamma$ RIIb and SIRP $\alpha$ (Fig. 2a). There was lower expression of $\mathrm{C} 1 \mathrm{r}, \mathrm{P}_{2} \mathrm{Y}_{6}, \mathrm{CX}_{3} \mathrm{CR} 1$, and TIM-3. (ii) Following I + T (M1) treatment, three stimulatory receptors increased (C1r, FcyRIIIa, TIM-3) and the inhibitory receptor, SIRP $\alpha$, decreased. While this might mean that M1 cells have a higher phagocytic capacity for a wider range of targets, there were concomitant decreases in the stimulatory receptors, SR-A, Fc $\gamma$ RIa, CD68, TREM2, and $\mathrm{CX}_{3} \mathrm{CR} 1$. (iii) After IL-4 treatment (M2a state), there were decreases in several stimulatory receptors (CD11b, SR-A, FcyRIa, CD68, TREM2) and an increase in the inhibitory receptor, Fc $\gamma$ RIIb, suggesting a reduced phagocytic capacity. However, $\mathrm{P}_{2} \mathrm{Y}_{6}$ increased and the inhibitory receptor, SIRP $\alpha$ decreased. Surprisingly, both M1 and M2a activation decreased SR-A, Fc $\gamma$ RIa, CD68, TREM2, and SIRP $\alpha$.

The complex changes in expression of phagocytosis-related receptors made predictions difficult. Thus, it was important to next assess whether myelin phagocytosis was affected by the activation state and, conversely, whether myelin altered receptor expression. (i) In unstimulated microglia, many receptors were unaffected by myelin $(\mathrm{CD} 11 \mathrm{~b}, \mathrm{SR}-\mathrm{A}$, Fc $\gamma$ RIa, Fc $\gamma$ RIIb, Fc $\gamma$ RIIIa, C1r, TREM2) or slightly decreased (CD68, SIRP $\alpha)$. However, there were increases in three receptors not known to mediate myelin phagocytosis: $\mathrm{P}_{2} \mathrm{Y}_{6}, \mathrm{CX}_{3} \mathrm{CR} 1$, and TIM-3. (ii) In I + T-treated cells, myelin increased the stimulatory receptors, $\mathrm{P}_{2} \mathrm{Y}_{6}$ and TIM-3 and, to a lesser extent, Fc $\gamma$ RIIIa and C1r. None were decreased. (iii) In IL-4-treated cells, myelin increased $\mathrm{P}_{2} \mathrm{Y}_{6}$ and $\mathrm{CX}_{3} \mathrm{CR} 1$, and although CD68 was slightly decreased, its mRNA counts remained very high. Interestingly, $\mathrm{P}_{2} \mathrm{Y}_{6}$ increased under all three activation states. Overall, effects of myelin were modest. (iv) Phagocytosis was unchanged by IL- 4 and increased $\sim 20 \%$ by I + T (Fig. 2b). Here, we also tested IL-10 to represent an M2c phenotype that is thought to resolve pro-inflammatory states (reviewed in $[18,19])$. We did not examine the molecular profile after IL-10 alone, mainly because the markers are less clear and some overlap with M1 markers [21]; however the IL-10-evoked increase in phagocytosis was similar to $\mathrm{I}+\mathrm{T}$. These small differences in phagocytosis are very unlikely to account for large differences in gene expression after exposure to myelin (Fig. 2a). 

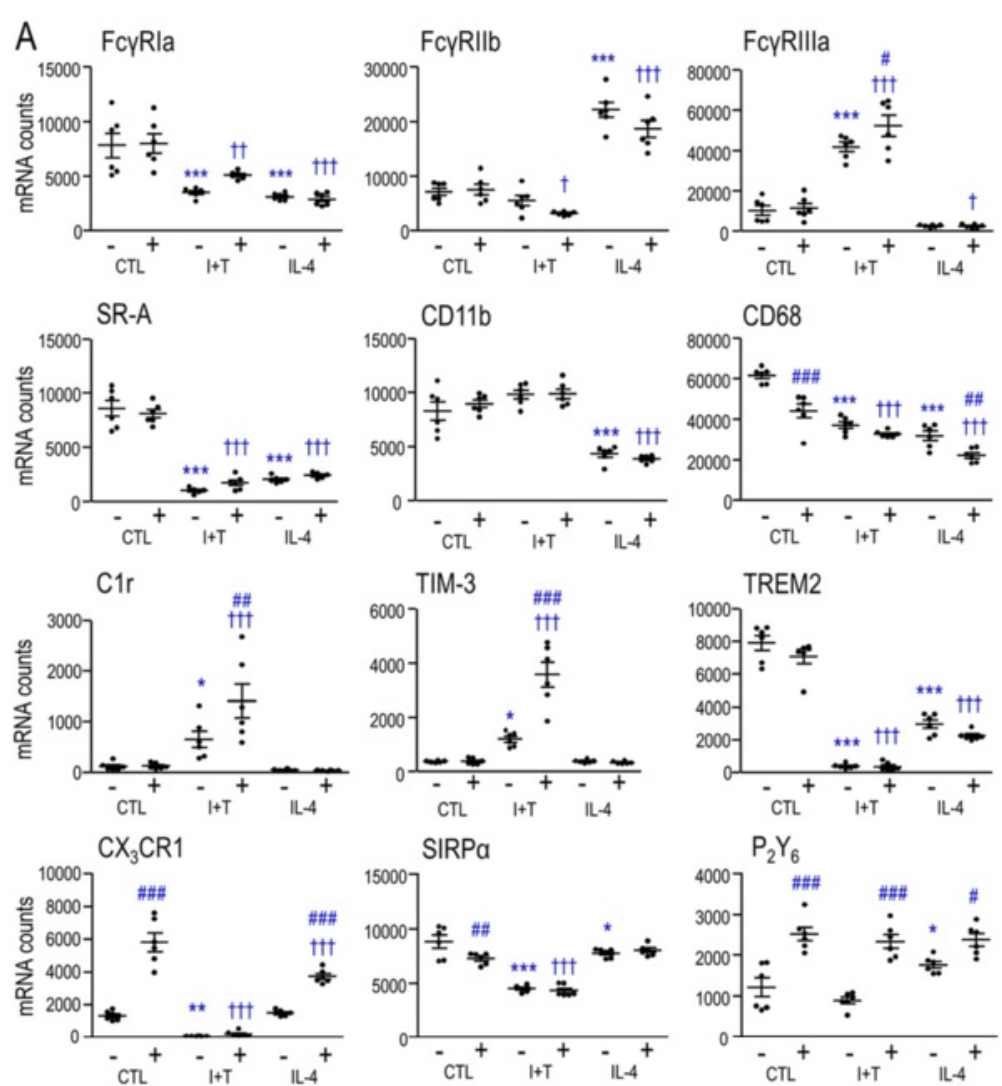

SIRPa
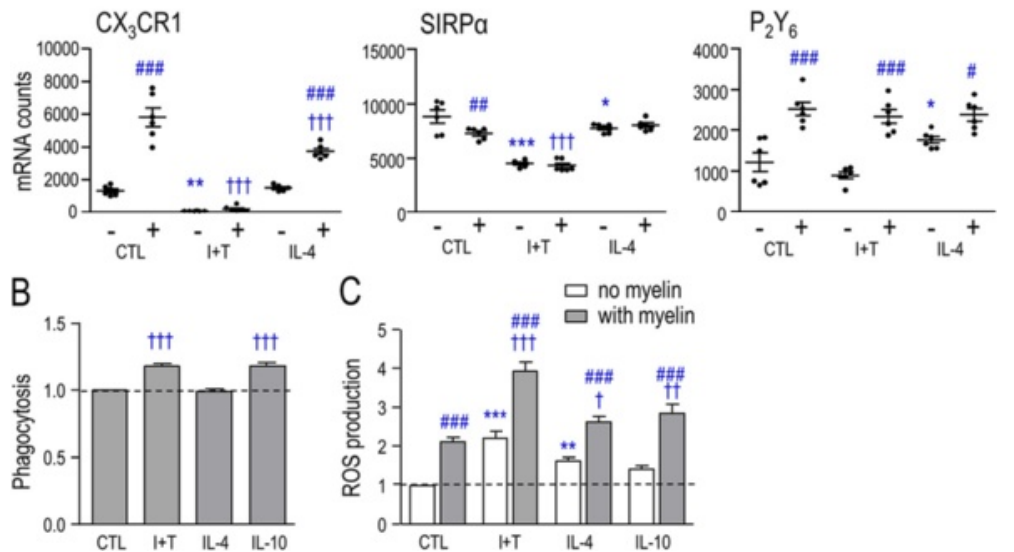

Fig. 2 Effects of microglial activation state on expression of phagocytosis-related molecules, phagocytosis, and ROS production. a Phagocytosis-related genes. Microglia were unstimulated (control, CTL) or stimulated for $24 \mathrm{~h}$ with $20 \mathrm{ng} / \mathrm{mL}$ IFN- $\gamma+50 \mathrm{ng} / \mathrm{mL}$ TNF-a (M1 activation state) or $20 \mathrm{ng} / \mathrm{mL}$ IL-4 (M2a state), with or without a subsequent 6-h exposure to $25 \mathrm{\mu g} / \mathrm{mL}$ myelin (plus or minus sign indicates presence/absence of myelin), as in Fig. 1a. Values are expressed as normalized mRNA counts (described in the "Methods" section), mean \pm SEM (six different cell cultures), and were analyzed by two-way ANOVA with Bonferroni's post hoc test. b Phagocytosis of myelin fragments. Microglia were exposed for $6 \mathrm{~h}$ to $25 \mu \mathrm{g} / \mathrm{mL}$ Dil-labeled myelin, and the amount of internalized myelin was determined in unstimulated (CTL), M1 (I + T), M2a (IL-4), and M2C (20 ng/mL IL-10)-stimulated microglia. Results were normalized to control microglia (dashed line) to determine activation state-dependent changes. Data are expressed as mean \pm SEM (20 individual cultures) and were analyzed by one-way ANOVA with Dunnett's post hoc test. c Production of reactive oxygen species (ROS). Intracellular ROS was monitored with the general ROS probe, dichlorofluorescein (DCF), and normalized to DCF levels in unstimulated (CTL) microglia without myelin (dashed line). Data were analyzed by two-way ANOVA with Bonferroni's post hoc test ( $n=19$ individual cultures). The comparisons are as follows. Asterisk Between unstimulated microglia (CTL) and cells treated with I $+\mathrm{T}$, IL-4, or IL-10. Dagger sign CTL versus different activation states in the presence of myelin. Number sign Effects of myelin within a particular activation state. One symbol $p<0.05$, two symbols $p<0.01$, three symbols $p<0.001$

The microglial activation state affects production of ROS and expression of ROS-related molecules

Phagocytosis is often accompanied by a considerable ROS production. Thus, we next compared ROS production in unstimulated (control) microglia and after $\mathrm{I}+\mathrm{T}$, IL-4, or IL-10, with and without myelin phagocytosis (Fig. 2c). Without myelin, ROS production increased in M1 (I+ T) and M2a (IL-4) states. Myelin phagocytosis further increased ROS production in all activation states.
Based on these changes in ROS production, we examined expression of several molecules related to ROS production. NADPH oxidase enzymes (NOX1-5) are homologs of NOX2/gp91phox, the catalytic subunit that is present in cell membranes [52]. It was previously reported that primary rat microglia express NOX1, NOX2, and NOX4, while NOX3 was not detected [53], and our results corroborate this (we did not examine NOX3). NOX2 is well-studied and is largely responsible for the 
phagocytosis-induced ROS production (respiratory burst) of microglia [4, 54] and other phagocytes [55]. Activation of NOX2 at the plasma membrane requires phosphorylation of the accessory subunit, Ncf1 (neutrophil cytosolic factor $1 / \mathrm{p} 47$ phox) $[56,57]$.

NOX2 and Ncf1 were highly expressed in unstimulated rat microglia, increased in M1-activated cells, and decreased in the M2a state (Fig. 3a). Myelin phagocytosis had minor effects, slightly decreasing NOX2 in the M1 state only. Our results are consistent with an earlier study of IFN- $\gamma$-stimulated microglia showing that myelin phagocytosis increased ROS production without affecting Ncf1 transcription [10]. NOX4 is unique in several respects. Its contribution is regulated by transcription without accessory subunits $[58,59]$, and it is located in membranes of the ER, nuclear envelope, and mitochondria [60]. We found that NOX4 expression was extremely low in unstimulated rat microglia and increased slightly in the M1 state only. NOX1 can contribute to production of both ROS and reactive nitrogen species [13], which are both involved in eradicating pathogens [55]. We found that NOX1 expression was always very low, was further decreased after I + T or IL-4 treatment, and was not affected by myelin phagocytosis. Thus, it seems most likely that NOX2 was responsible for the observed changes in ROS production (Fig. 2). The voltage-gated proton channel, Hv1, was also examined because it can facilitate ROS production by allowing $\mathrm{H}^{+}$efflux as charge compensation for NOX-generated electrons [61, 62]. Hv1 was moderately expressed in unstimulated microglia and increased in the
M1 state. Overall, only the M1 stimulus increased known facilitators of ROS production in microglia. Myelin phagocytosis further increased Hv1 in unstimulated and M1activated cells.

We then used the pan-NOX inhibitor VAS2870 [63] to assess overall contributions of NOX enzymes. The drug was non-toxic. In control cells and in all three activation states, VAS2870 decreased phagocytosis to below the level of unstimulated microglia (Fig. 3b). Exposure to myelin always increased ROS production (as in Fig. 2c), and this was essentially abolished by VAS2870 in all three activated states (Fig. 3c). (Statistical comparisons of phagocytosis in different activation states were shown in Fig. 2.)

\section{Attempting to repolarize microglia using sequential cytokine stimulation}

To model a changing inflammatory environment, such as can occur after CNS injury (see Background), we used sequential addition of cytokines that induce M1 then M2 activation and vice versa. The same panel of inflammatory, phagocytosis-related, and oxidative stressrelated genes was assessed as in Figs. 1, 2, and 3. (i) Microglia were stimulated with IL-4 followed by I + T, which we refer to as an "M2a $\rightarrow \mathrm{M} 1$ " stimulus paradigm (Fig. 4a). Several changes were consistent with $\mathrm{I}+\mathrm{T}$ skewing (re-polarizing) them toward an M1 state. Two M2 markers (MRC1, CD163) were dramatically reduced (to control levels), and three pro-inflammatory mediators (NOS2, TNF- $\alpha, \mathrm{COX} 2$ ) were higher than with IL-4 alone. The cells were not fully re-polarized to M1, as
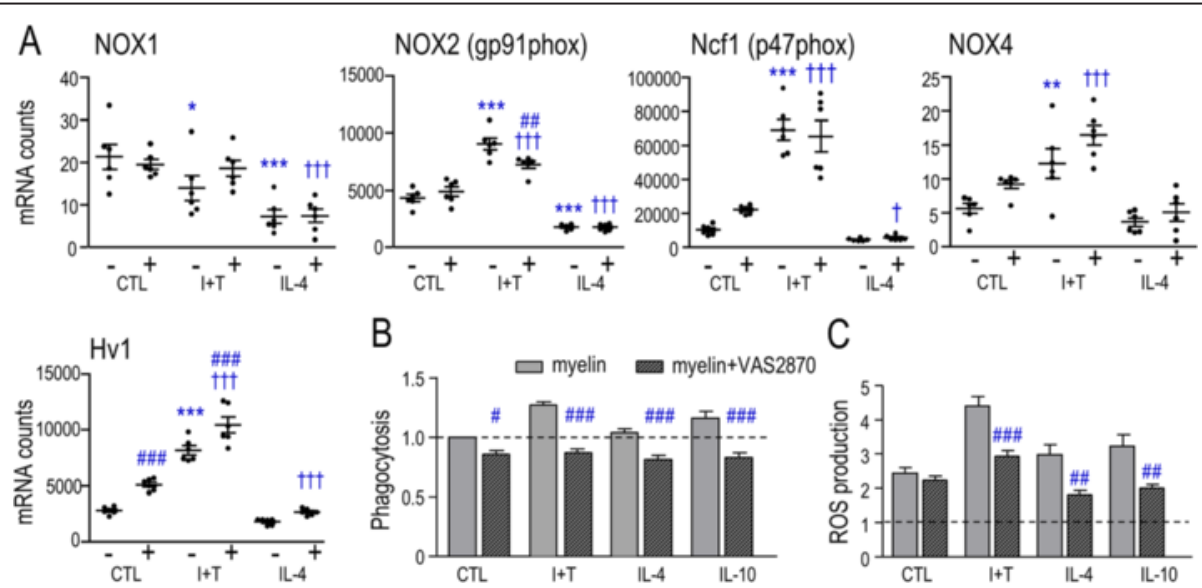

B

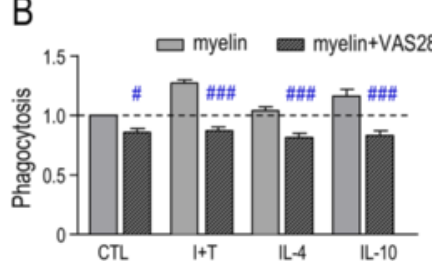

C

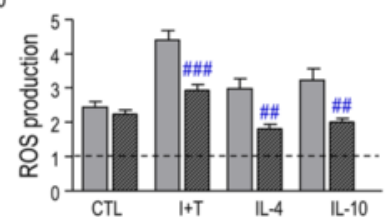

Fig. 3 Expression of ROS-related molecules and contribution of NOX enzymes to myelin phagocytosis and ROS production. a Expression of ROS-related molecules. Rat microglia were stimulated with cytokines for $24 \mathrm{~h}$ with or without a subsequent 6-h exposure to myelin (p/us or minus sign indicates presence/absence of myelin), as in Figs. 1a and 2a. $\mathbf{b}$ Effect of NOX inhibition on phagocytosis of myelin fragments. The activation treatments, assay, and normalization of data were the same as Fig. 2b, but now comparing the pan-NOX inhibitor, 5 MM VAS2870. c Effect of NOX inhibition on ROS levels in microglia that were treated as in Fig. 2b. As above, ROS levels were normalized to unstimulated microglia without myelin (dashed line), data are expressed as mean \pm SEM ( $n=6$ individual cultures), and results were analyzed by two-way ANOVA with Bonferroni's post hoc test. The comparisons are as follows: asterisk unstimulated $(C T L)$ versus different activation states in the absence of myelin, dagger sign unstimulated (CTL) versus different activation states in the presence of myelin, number sign effects of myelin $(\mathbf{a})$ or VAS2870 (b, $\mathbf{c})$ within a particular activation state. One symbol $p<0.05$, two symbols $p<0.01$, three symbols $p<0.001$ 

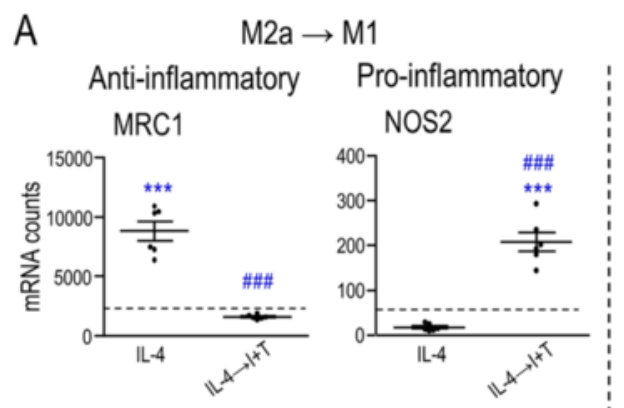

B $\quad \mathrm{M} 1 \rightarrow \mathrm{M} 2 \mathrm{a} / \mathrm{C}$
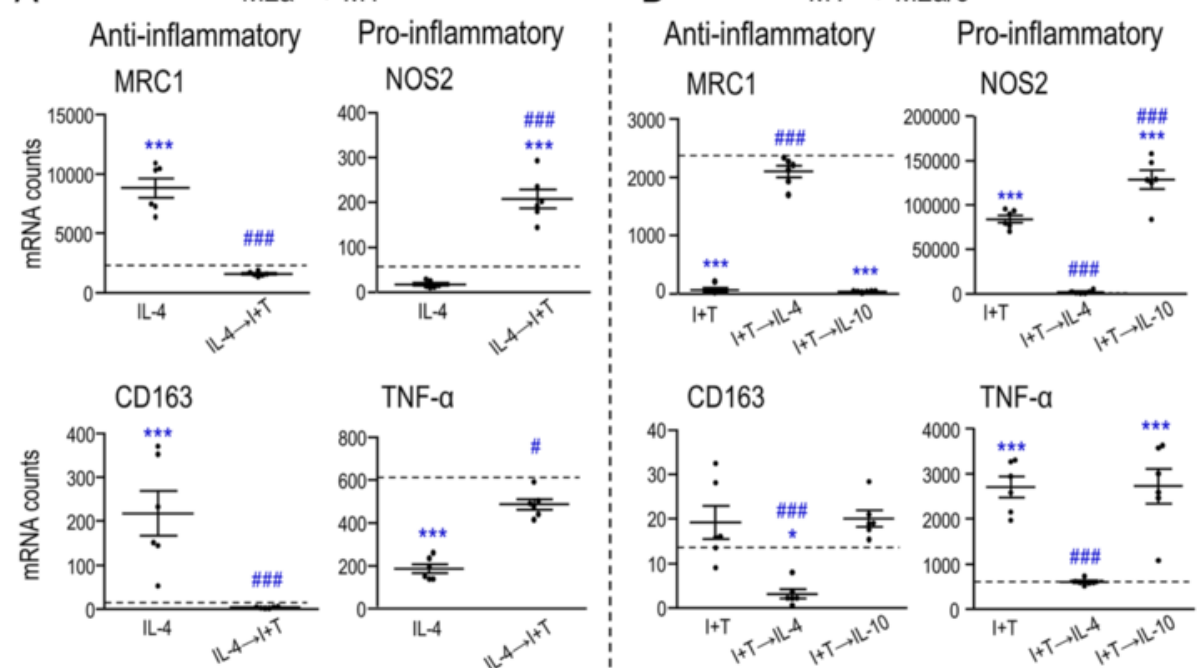

TNF-a
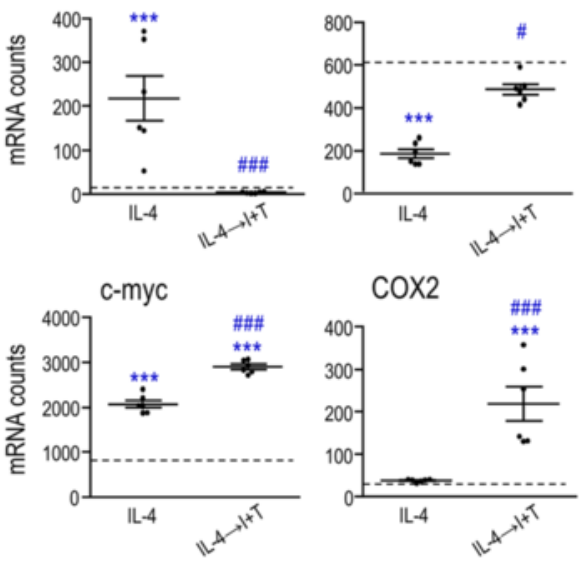

CD163

TNF- $a$
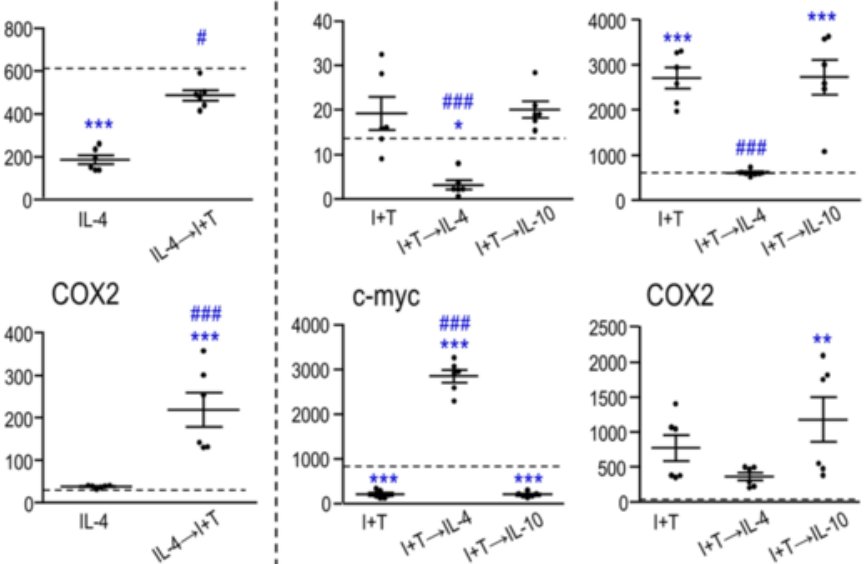

$\operatorname{cox} 2$

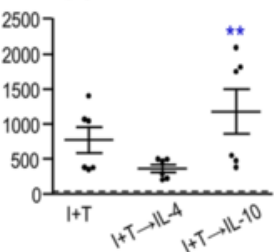

CCL22

IL-6
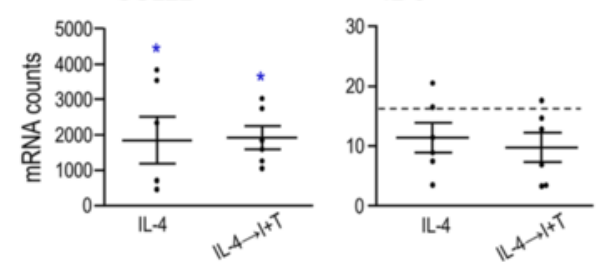

CCL22
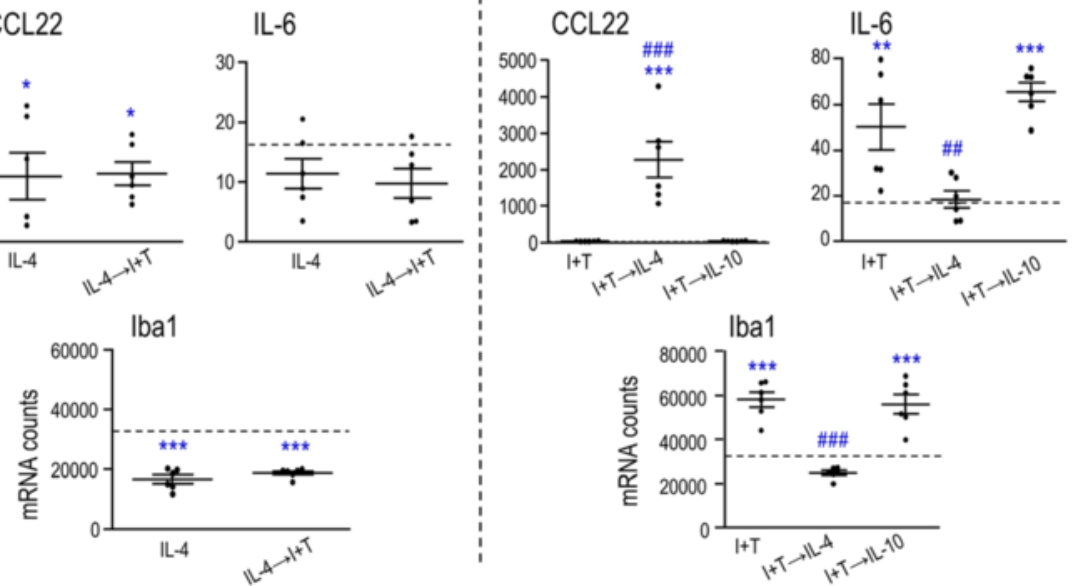

Fig. 4 Repolarizing the inflammatory profile of microglia using sequential cytokine addition. a "M2a $\rightarrow M 1$ " stimulus paradigm. Microglia were treated with $20 \mathrm{ng} / \mathrm{mL} \mathrm{IL}-4$ for $2 \mathrm{~h}$ followed by $20 \mathrm{ng} / \mathrm{mL} \mathrm{IFN}-\mathrm{\gamma}+50 \mathrm{ng} / \mathrm{mL}$ TNF-a $(\mathrm{I}+\mathrm{T})$ for $22 \mathrm{~h}$. b "M1 $\rightarrow \mathrm{M2}$ " stimulus paradigm. Microglia were treated with I+T for $2 \mathrm{~h}$ followed by either IL-4 ("M1 $\rightarrow \mathrm{M} 2 \mathrm{a}^{\prime \prime}$ ) or $20 \mathrm{ng} / \mathrm{mL} \mathrm{IL}-10$ ("M1 $\left.\rightarrow \mathrm{M} 2 \mathrm{c}^{\prime \prime}\right)$ for $22 \mathrm{~h}$. Data are expressed as mRNA counts in $200 \mathrm{ng}$ total RNA (mean \pm SEM, $n=6$ individual cultures) and were analyzed by one-way ANOVA with Tukey's post hoc test. The dashed lines indicate expression levels in unstimulated (control) microglia. (Some lines are too low to see.) The comparisons are as follows: asterisk differences from control microglia, number sign effects of a secondary stimulus on the first stimulus. One symbol $p<0.05$, two symbols $p<0.01$, three symbols $p<0.001$

some pro-inflammatory genes remained lower than with $\mathrm{I}+\mathrm{T}$ alone: NOS2/iNOS (a 3.6-fold increase vs 1444 fold), Iba1 (0.6 vs 1.8 fold), TNF- $\alpha$ (0.8 vs 4.3 fold), and COX-2 (7.1 vs 25.9 fold). Not all genes were affected. The changes in IL- 6 and CCL22 were not different from IL-4 alone. While c-myc was increased in the M2a $\rightarrow$ M1 stimulus paradigm, the change was small (3.6 vs 2.5 fold). (ii) In the reverse paradigm, the cells were first stimulated with I $+\mathrm{T}$, followed by IL-4 or IL-10 (Fig. 4b). Secondary IL-4 treatment (M1 $\rightarrow$ M2a paradigm) generally dampened the M1 response and further skewed microglia toward an anti-inflammatory $\mathrm{M} 2 \mathrm{a}$ state relative to $\mathrm{I}+\mathrm{T}$ alone. That is, IL-4 prevented induction of Iba1 and down-regulated several pro-inflammatory 
molecules; NOS2 (5.9 vs 1444 fold), TNF- $\alpha$ (1.0 vs 4.3 fold), and IL-6 (1.1 vs 3.1 fold). It also increased expression of some M2a-associated molecules; CCL22 (151 vs 2.1 fold), c-myc ( 3.5 vs 0.2 fold), and MRC1 ( 0.9 vs 0.03 fold). Overall, some re-polarization of the activation state was evident between M1 and M2a. In contrast, secondary IL-10 treatment (M1 $\rightarrow$ M2c paradigm) failed to reverse any $\mathrm{I}+\mathrm{T}$-induced changes, and instead, it increased expression of NOS2.

Next, we examined the same phagocytosis-related (Fig. 5) and ROS-related molecules (Fig. 6) as in Figs. 2 and 3. (i) In the M2a $\rightarrow \mathrm{M} 1$ stimulus paradigm (Fig. 5a), there was a dampened response compared with IL-4 alone. Eight out of 12 phagocytosis-related receptors decreased, including 6 stimulatory receptors (CD11b, SRA, CD68, TREM2, CX 3 CR1, TIM-3) and 2 inhibitory receptors (Fc $\gamma$ RIIb, SIRP $\alpha)$. Three stimulatory receptors were unchanged (Fc $\gamma$ RIa, Fc $\gamma$ RIIIa, C1r), and only $\mathrm{P}_{2} \mathrm{Y}_{6}$ increased. For ROS-related molecules, Ncf1 increased but the others generally decreased (Fig. 6a). (ii) In the $\mathrm{M} 1 \rightarrow \mathrm{M} 2 \mathrm{a}$ paradigm (Fig. 5b), compared with $\mathrm{I}+\mathrm{T}$ alone, there was a dampened response of several stimulatory receptors (CD11b, FcyRIIIa, CD68, C1r, TIM-3), the inhibitory receptor, SIRP $\alpha$, and all ROS-related genes (Fig. 6b). Genes that were unchanged were the stimulatory receptors, SR-A, FcyRIa, and TREM2, and the inhibitory receptor, FcyRIIb. Again, only $\mathrm{P}_{2} \mathrm{Y}_{6}$ was increased. (iii) The $\mathrm{M} 1 \rightarrow \mathrm{M} 2 \mathrm{c}$ paradigm did not dampen responses compared with $\mathrm{I}+\mathrm{T}$ alone, except for a small decrease in Ncf1 (Figs. 5b and 6b). Instead, there were increases in 5/17 phagocytosis- and ROS-related molecules: NOX4, the stimulatory receptors, CD11b, Fc $\gamma$ RIIIa, and TIM-3, and the inhibitory receptor, SIRP $\alpha$. Together, these results indicate substantial repolarization in the $\mathrm{M} 2 \mathrm{a} \rightarrow \mathrm{M} 1$ and $\mathrm{M} 1 \rightarrow \mathrm{M} 2 \mathrm{a}$ paradigms but not the $\mathrm{M} 1 \rightarrow$ M2c paradigm.

The observed changes in expression of phagocytosisand ROS-related genes led us to directly examine myelin phagocytosis and ROS production following sequential treatments with M2 and M1 stimuli. (i) M2 $\rightarrow$ M1: When IL-4 (M2a) - or IL-10 (M2c)-treated microglia were subsequently treated with $\mathrm{I}+\mathrm{T}$, both phagocytosis and ROS production increased compared with IL-4 or IL-10 alone (Fig. 7a), which suggests that some re-polarization occurred. (ii) $\mathrm{M} 1 \rightarrow \mathrm{M} 2$ : In the reverse paradigm ( $+\mathrm{T}$, then IL-4 or IL-10), phagocytosis was slightly increased by IL-4 (M1 $\rightarrow$ M2a) but not by IL-10 (M1 $\rightarrow$ M2c). ROS production was unchanged compared with $\mathrm{I}+\mathrm{T}$ alone (Fig. 7b). (iii) Myelin effects: Without myelin, I+ T increased ROS and subsequently adding IL-4 or IL-10 had no further effect; whereas, adding I + T after IL-4 or IL10 increased ROS production. Adding myelin always increased ROS production compared with control cells (no treatment, no myelin). In the presence of myelin, there was some functional re-polarization from $\mathrm{M} 2 \mathrm{a} / \mathrm{c} \rightarrow \mathrm{M} 1$ (increased phagocytosis and ROS production). In contrast, compared with $\mathrm{I}+\mathrm{T}$ alone, ROS production was not altered by $\mathrm{M} 1 \rightarrow \mathrm{M} 2 \mathrm{a}$ (which slightly increased phagocytosis) nor M1 $\rightarrow$ M2c (which did not).

NOX enzymes were involved in both myelin phagocytosis and ROS production under almost all conditions (Fig. 7c). That is, the NOX inhibitor, VAS2870, decreased myelin phagocytosis under all conditions and decreased ROS production in all stimulated cells (but not in control cells).

\section{Expression of $\mathrm{K}^{+}$and CRAC channels and their} contributions to myelin phagocytosis and ROS production Rat microglia express several $\mathrm{K}^{+}$channels, including KCa3.1, Kv1.3, and Kir2.1, as well as store-operated $\mathrm{Ca}^{2+}$ entry (SOCE) channels. Pore-forming Orai1 and accessory STIM1 subunits form CRAC channels, while Orai3 and STIM2 are also involved in SOCE [64]. We first examined whether expression of these channels differs in M1 and M2 microglial activation states and whether it is altered by myelin phagocytosis (Fig. 8a). (i) In unstimulated (control) cells, the only change evoked by myelin was an increase in Kv1.3 expression. (ii) I + T (M1) stimulation increased expression of all the genes examined (except Orai1), i.e., KCa3.1 (1.8 fold), Kv1.3 (2.3 fold), Kir2.1 (5.2 fold), Orai3 (2.2 fold), STIM1 (2.2 fold), and STIM2 (1.2 fold) (Fig. 8a). In $\mathrm{I}+\mathrm{T}$ treated cells, myelin phagocytosis increased expression of KCa3.1, Kv1.3, Orai1, and Orai3. (iii) IL-4 (M2a) stimulation increased expression of KCa3.1 (2.1 fold) and Kv1.3 (1.6 fold) and decreased STIM2 (by $26 \%$ ). It did not affect Kir2.1, Orai1, Orai3, or STIM1. Myelin phagocytosis did not alter any of these genes. (iv) In the $\mathrm{M} 2 \mathrm{a} \rightarrow \mathrm{M} 1$ paradigm (IL-4 then I + T; Fig. 8b), all the genes decreased to the control level or lower, except Kir2.1. (v) In the $\mathrm{M} 1 \rightarrow \mathrm{M} 2 \mathrm{a}$ paradigm ( $+\mathrm{T}$ then IL-4; Fig. 8c), all the genes (except Orai1) decreased compared with $\mathrm{I}+\mathrm{T}$ and were then at or below the control level. (vi) In the M1 $\rightarrow$ M2c paradigm (I + T then IL-10; Fig. 8c), IL-10 did not exert the same effects as IL-4. KCa3.1 was slightly elevated compared with $\mathrm{I}+\mathrm{T}$ but no other genes were affected.

A panel of ion channel blockers was used to assess their involvement in myelin phagocytosis and ROS production. Blocking KCa3.1 (Fig. 9a) or Kv1.3 (Fig. 9b) did not alter myelin phagocytosis or ROS production under any activation state tested. Blocking Kir2.1 had no effect on control cells (Fig. 9c) but it abolished the increase in phagocytosis under all activation paradigms. Most striking was that whenever $\mathrm{I}+\mathrm{T}$ was present, Kir2.1 block reduced the myelin-induced increases in ROS production. CRAC channel inhibition greatly decreased myelin phagocytosis under all activation paradigms (Fig. 9d). 

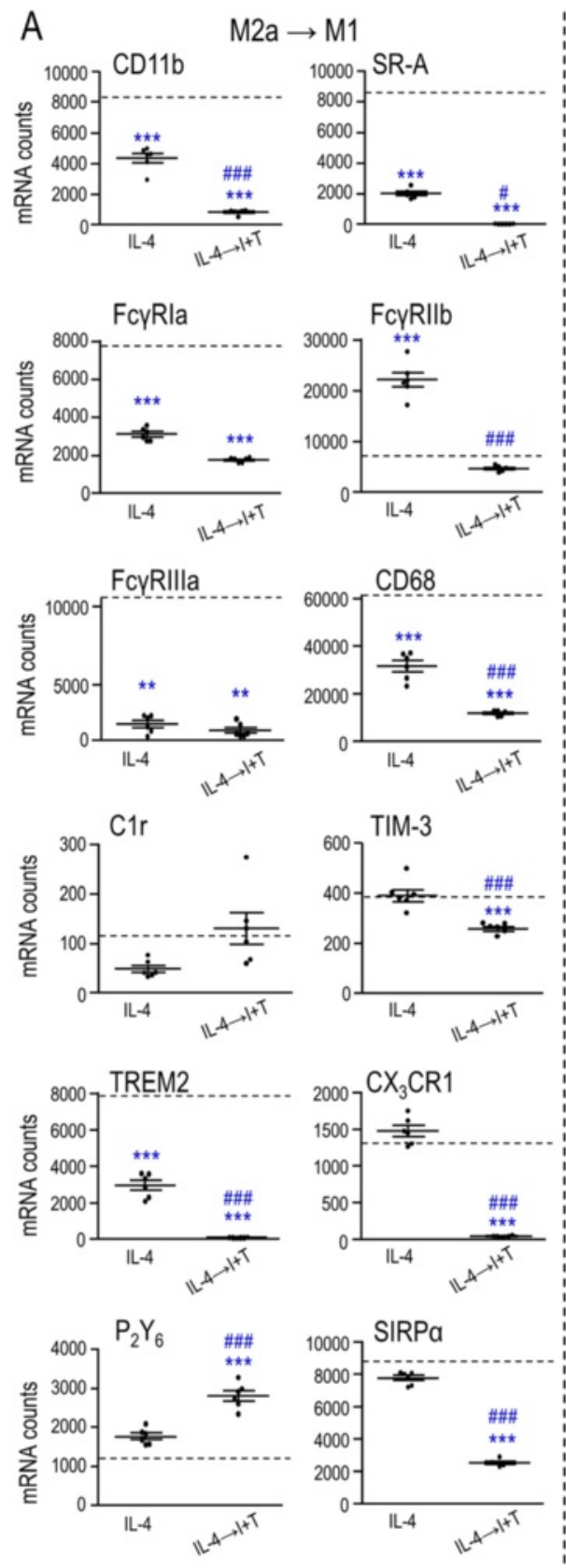

Fig. 5 Sequential cytokine addition affects expression of phagocytosis-related molecules. a M2a $\rightarrow$ M1 paradigm. Microglia were treated with 20 ng/mL IL-4 for $2 \mathrm{~h}$ followed by $20 \mathrm{ng} / \mathrm{mL}$ IFN- $\gamma+50 \mathrm{ng} / \mathrm{mL}$ TNF-a $(\mathrm{I}+\mathrm{T})$ for $22 \mathrm{~h}$. b M1 $\rightarrow \mathrm{M} 2$ paradigm. Microglia were treated with I $+\mathrm{T}$ for $2 \mathrm{~h}$ followed by either $\mathrm{IL}-4(\mathrm{M} 1 \rightarrow \mathrm{M} 2 \mathrm{a})$ or $20 \mathrm{ng} / \mathrm{mL} \mathrm{IL-10} \mathrm{(M1} \rightarrow \mathrm{M} 2 \mathrm{c}$ ) for $22 \mathrm{~h}$. Data are expressed as mRNA counts in 200 ng total RNA (mean \pm SEM, $n=6$ individual cultures) and were analyzed by one-way ANOVA with Tukey's post hoc test. The dashed lines indicate expression levels in unstimulated (control) microglia. The comparisons are as follows: asterisk differences from control microglia, number sign effects of the second stimulus on the first stimulus. One symbol $p<0.05$, two symbols $p<0.01$, three symbols $p<0.001$

ROS production was also reduced, except in control and IL-10-treated cells, where the CRAC blocker showed a trend toward a decrease that did not reach statistical significance. However, the myelin-stimulated ROS component was relatively small under these conditions, and there was less likelihood of seeing a blocker effect. There
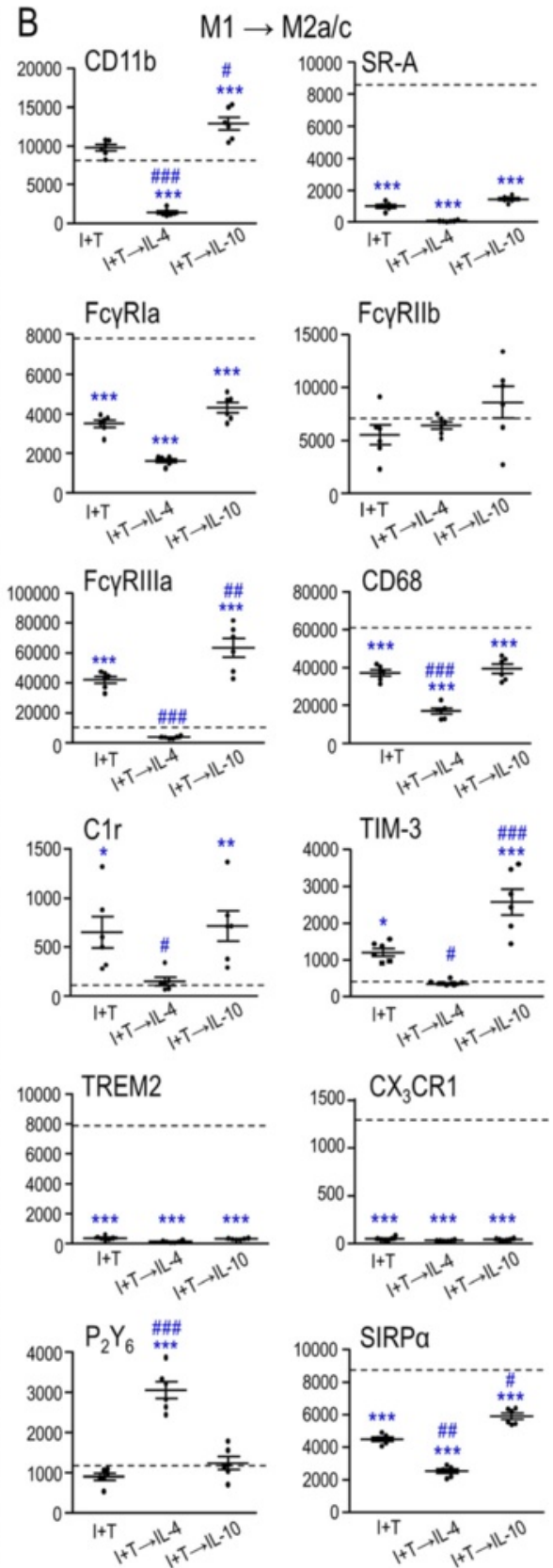


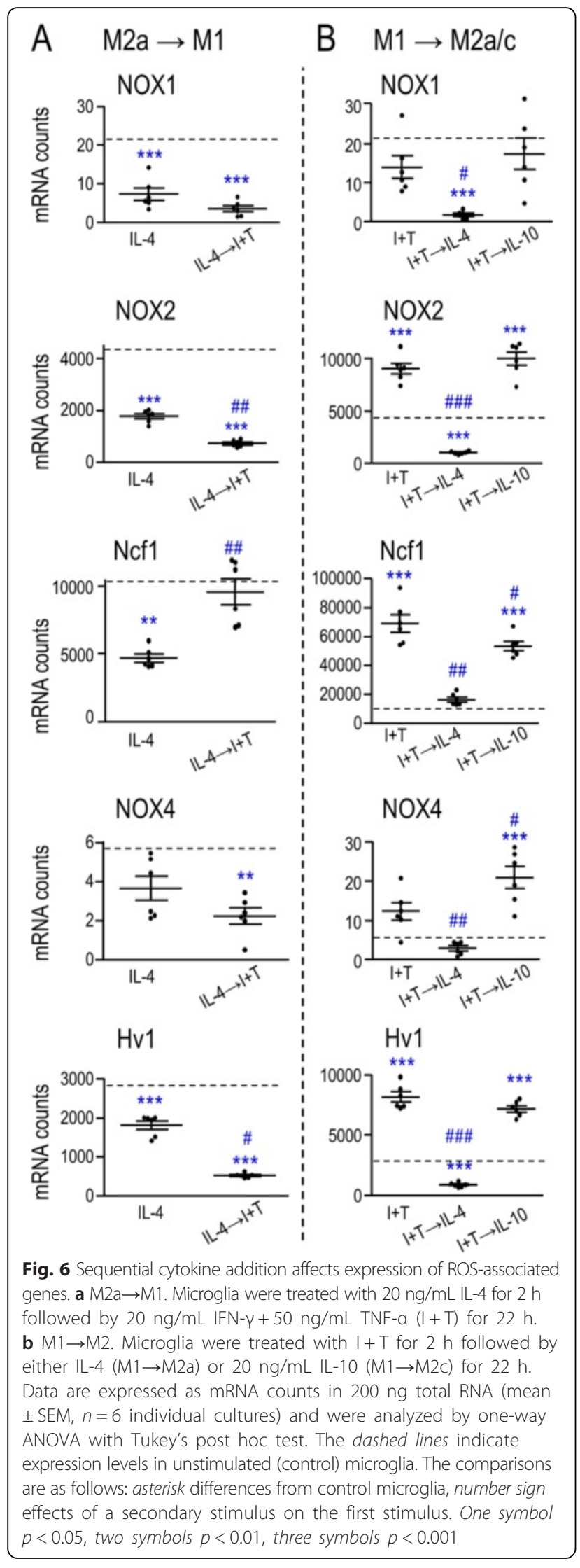

component. Overall, expression of all four ion channels was affected by the activation state, but only Kir2.1 and CRAC channels were involved in myelin phagocytosis and the consequent respiratory burst.

\section{Discussion}

This study used gene profiling and functional analyses to examine relationships between microglial activation states, myelin phagocytosis and ROS production, and the role of selected ion channels in these processes. Because the treatments and outcomes examined were complex, for clarity in comparing with previous studies, the salient findings will be discussed under four topics: (1) outcomes of single stimuli used to polarize microglia to different activation states, (2) effects of myelin phagocytosis on their activation state, (3) attempts to re-polarize microglial activation, and (4) expression and contributions of the ion channels in different activation states.

\section{Effects of single stimuli}

The first step was to validate the procedures used to stimulate primary rat microglia. In agreement with wellknown markers [17-20], we found that IFN- $\gamma$ combined with TNF- $\alpha(\mathrm{I}+\mathrm{T})$ induced a pro-inflammatory M1-like state, while IL-4 induced an anti-inflammatory (M2a) state. Thus, the cytokine concentrations we used were effective in changing the molecular inflammatory profile, as measured at $24 \mathrm{~h}$.

It is expected that phagocytosis by activated microglia will depend on the target, whether it is opsonized, and which phagocytosis-related receptors are engaged. For instance, in the damaged CNS, if extravasation of complement or antibodies occurs, this can engage CR3 and $\mathrm{Fc} \gamma$ receptors, respectively. Furthermore, under in vitro conditions, if complement is present (i.e., if serum is not heat-inactivated), this can greatly promote myelin phagocytosis [32]. We previously showed that unstimulated rat microglia can phagocytose polymer beads, yeast, and Escherichia coli bacteria [11, 29, 65] and that E. coli phagocytosis was robustly increased by LPS and IFN- $\gamma$, separately or in combination [29]. Here, untreated rat microglia robustly phagocytosed myelin, and this was modestly increased by I + T (M1) and IL-10 (M2c), but not by IL-4 (M2a). Our results are entirely consistent with an earlier study of rat microglia, in which stimulation with mouse recombinant IFN- $\gamma$, TNF$\alpha$, or IL-10 (note species mismatch) increased myelin phagocytosis, but IL-4 did not [22]. In contrast, IL-4 or IL-13 stimulation increased phagocytosis of myelin by human microglia [23] and of apoptotic cells by rat microglia [66].

We next asked whether there were changes in expression of specific phagocytosis-related receptors in different activation states. (i) For M1 stimulation, previous 

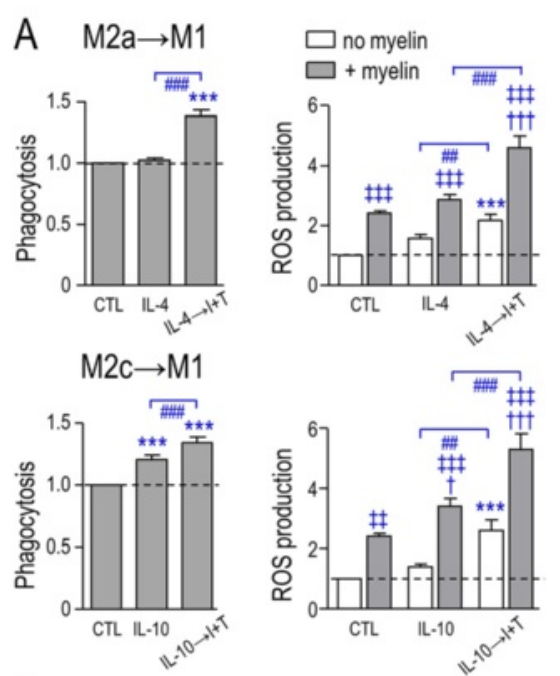

B $\quad \mathrm{M} 1 \rightarrow \mathrm{M} 2 \mathrm{a}$
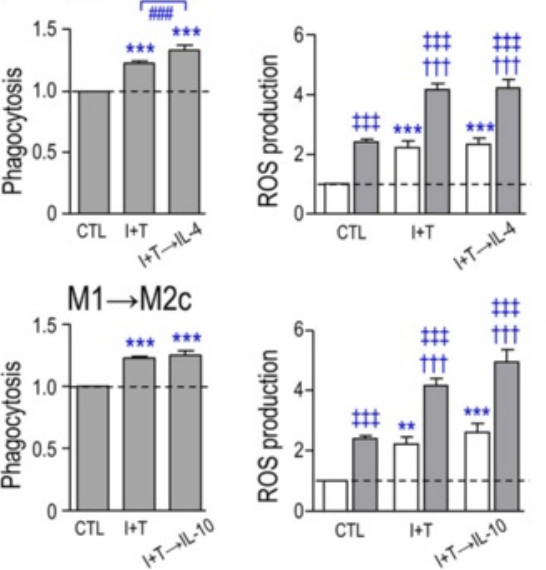

myelin

myelin+VAS2870

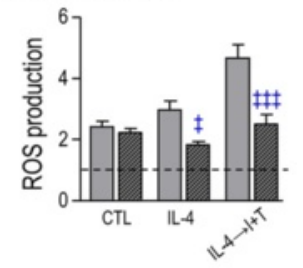

$\mathrm{M} 2 \mathrm{c} \rightarrow \mathrm{M} 1$
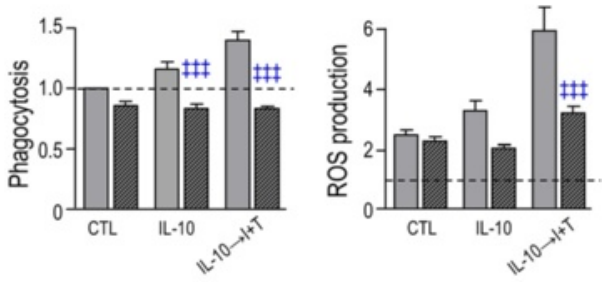

$\mathrm{M} 1 \rightarrow \mathrm{M} 2 \mathrm{a}$
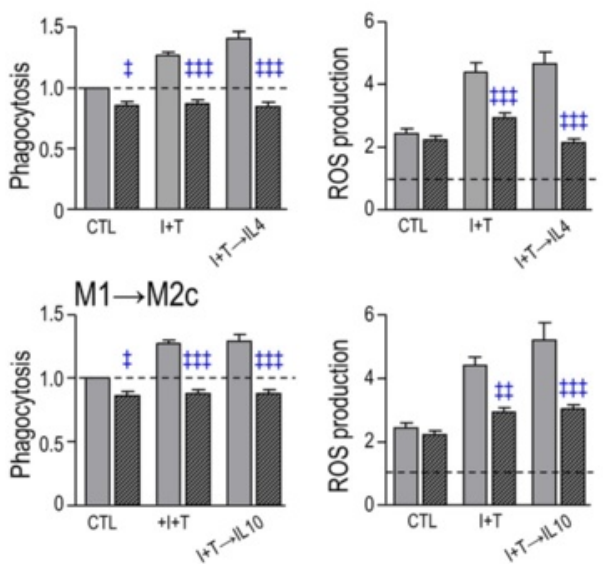

Fig. 7 Sequential cytokine addition affects myelin phagocytosis and NOX-mediated ROS production. Data are presented as mean \pm SEM; $n=12$ $(\mathbf{a}, \mathbf{b}), n=6(\mathbf{c})$. Data were normalized to unstimulated (CTL) microglia (indicated by dashed lines) in the presence of myelin (for phagocytosis) or without myelin (for ROS production). a M2 $\rightarrow$ M1. Microglia were first stimulated with $20 \mathrm{ng} / \mathrm{mL} \mathrm{IL-4} \mathrm{(M2a)} \mathrm{or} 20 \mathrm{ng} / \mathrm{mL} \mathrm{IL}-10$ (M2C) for $2 \mathrm{~h}$ and then with $20 \mathrm{ng} / \mathrm{mL}$ IFN- $\gamma+50 \mathrm{ng} / \mathrm{mL}$ TNF-a $(\mathrm{I}+\mathrm{T}$; M1) for an additional $22 \mathrm{~h} . \mathbf{b} \mathrm{M} 1 \rightarrow \mathrm{M} 2 . \mathrm{I}+\mathrm{T}$ was added for $2 \mathrm{~h}$, followed by IL-4 (M1 $\rightarrow$ M2a) or $\mathrm{IL}-10(\mathrm{M} 1 \rightarrow \mathrm{M} 2 \mathrm{C})$ for a further $22 \mathrm{~h}$. For $\mathbf{a}$ and $\mathbf{b}$, Dil-labeled myelin $(25 \mu \mathrm{g} / \mathrm{mL})$ was added to cultures $24 \mathrm{~h}$ after adding the first cytokine, and both phagocytosis and intracellular ROS levels were assessed $6 \mathrm{~h}$ later (as in Figs. 2b,c and 3b,c). c Effect of NOX inhibition on myelin phagocytosis and ROS production in microglia that were stimulated as in $\mathbf{a}$ and $\mathbf{b}$. Microglia were incubated with $25 \mu \mathrm{g} / \mathrm{mL}$ myelin for $6 \mathrm{~h}$, with or without the pan-NOX inhibitor, 5 MM VAS2870. Results were analyzed by a one-way ANOVA (for phagocytosis in a) or a two-way ANOVA (for ROS and phagocytosis in c) with Bonferroni's post hoc test. The comparisons are as follows. Asterisk Differences from unstimulated (CTL) microglia. Dagger sign CTL versus different activation states in the presence of myelin. Number sign Differences within (or among) different activation states. Double dagger sign Effects of myelin (a, b) or VAS2870 (c) within or between activation states. One symbol $p<0.05$, two symbols $p<0.01$, three symbols $p<0.001$

reports are inconsistent and possibly species dependent. Some changes seen in rat microglia are expected to increase their phagocytic capacity. Our earlier study found that LPS increased Fc $\gamma$ RIa and Fc $\gamma$ RIIIa, while phagocytosis of E. coli increased CR3 and SR-A [29]. The stimulatory phagocytic receptor, FcyRIIIa, is often used as an M1 marker [67, 68]. We found that I + T (M1) increased FcyRIIIa, as well as TIM-3, which promotes phagocytosis of apoptotic neurons [51]. Other changes might dampen the phagocytic capacity, but again, there are possible species differences, e.g., LPS reduced FcyRIIIa in murine microglia [21]. The TREM2 receptor aids in target internalization by microglia $[69,70]$. We found that $\mathrm{I}+\mathrm{T}$ dramatically decreased TREM2 in rat microglia; however, LPS increased it in murine microglia [71]. Fractalkine $\left(\mathrm{CX}_{3} \mathrm{CL} 1\right)$ is an important chemotactic signal released by apoptotic cells [72] but in rat microglia, LPS decreased its receptor, $\mathrm{CX}_{3} \mathrm{CR} 1$ [73], as did I + T in the present study. Based on the changes we observed with M1 stimulation (and lack of changes in FcyRIIb, CD11b, $\mathrm{P}_{2} \mathrm{Y}_{6}$ ), we suggest that the most likely contributors to increased myelin phagocytosis were the reduced inhibitory 

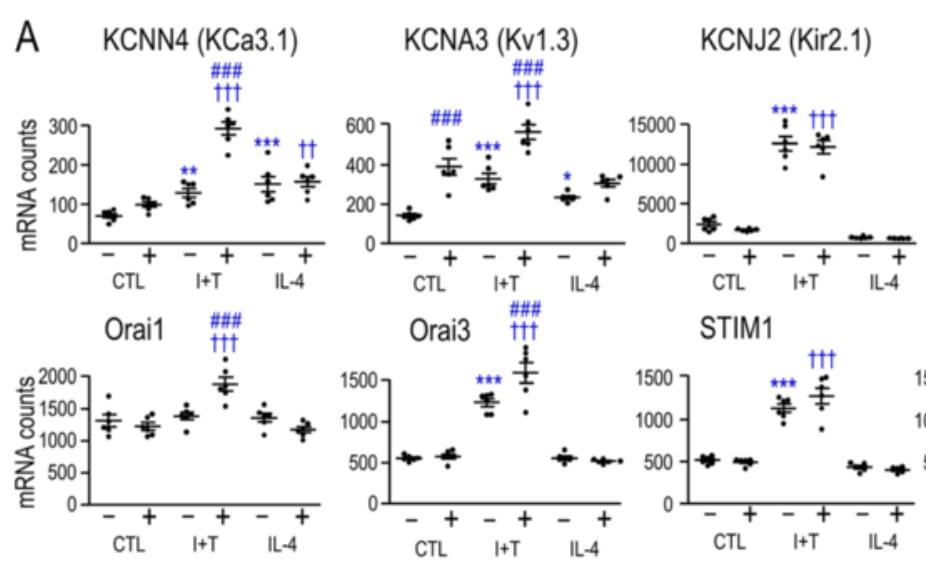

STIM1

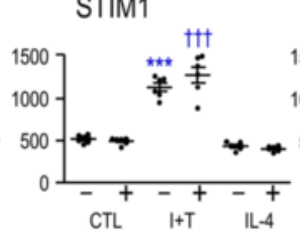

STIM2

$\mathrm{B} \quad \mathrm{M} 2 \mathrm{a} \rightarrow \mathrm{M} 1$
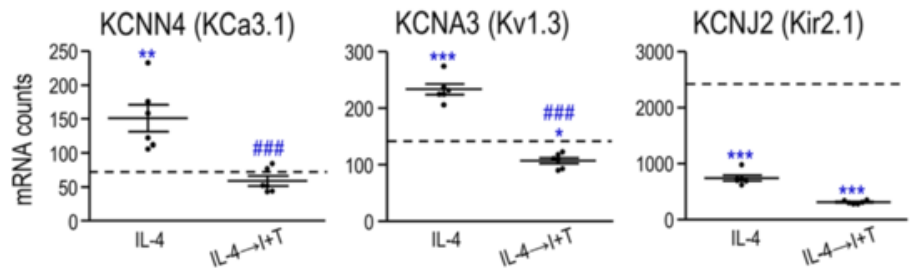

Orai1
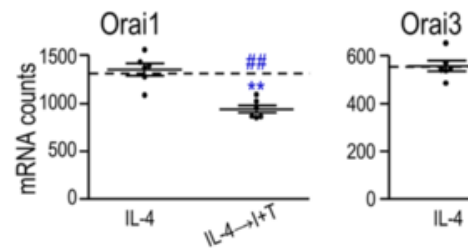

STIM1
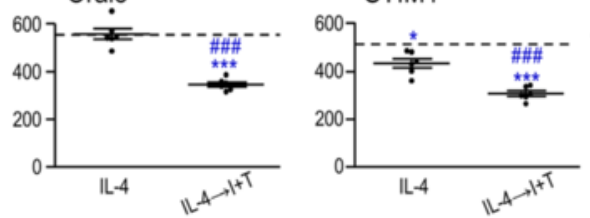

STIM2

C $\mathrm{M} 1 \rightarrow \mathrm{M} 2 \mathrm{a} / \mathrm{C}$
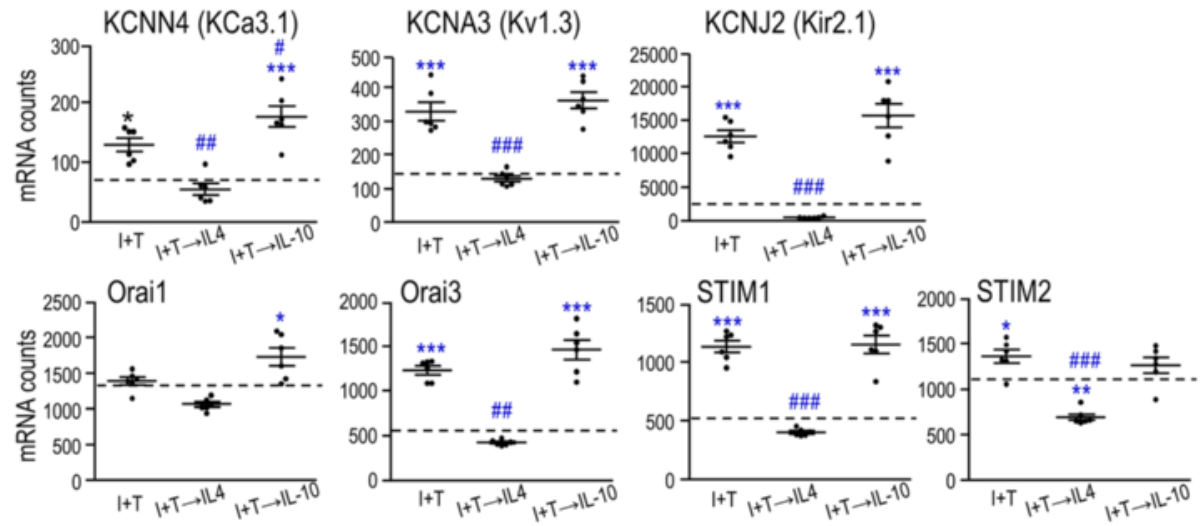

Fig. 8 Transcript expression of $\mathrm{K}^{+}$channels and SOCE-related genes is affected by the microglial activation state and myelin phagocytosis. a Single cytokines with or without myelin. Microglia were stimulated for $24 \mathrm{~h}$ with $20 \mathrm{ng} / \mathrm{mL} \mathrm{IFN}-\gamma+50 \mathrm{ng} / \mathrm{mL}$ TNF-a $(I+T)$ or $20 \mathrm{ng} / \mathrm{mL}$ $\mathrm{IL}-4$, and then treated with $25 \mathrm{\mu g} / \mathrm{mL}$ myelin for $6 \mathrm{~h}$. b M2a $\rightarrow \mathrm{M} 1$ paradigm. Microglia were treated with $20 \mathrm{ng} / \mathrm{mL} \mathrm{IL}-4$ for $2 \mathrm{~h}$ followed by $\mathrm{I}+\mathrm{T}$ for $22 \mathrm{~h}$. c M1 $\rightarrow \mathrm{M} 2$ paradigm. Cells were treated with I $+\mathrm{T}$ for $2 \mathrm{~h}$ followed by IL-4 (M1 $\rightarrow \mathrm{M} 2 \mathrm{a}$ ) or $20 \mathrm{ng} / \mathrm{mL} \mathrm{IL}-10$ (M1 $\rightarrow \mathrm{M} 2 \mathrm{c})$ for $22 \mathrm{~h}$. All data are expressed as mRNA counts in $200 \mathrm{ng}$ total RNA (mean \pm SEM) for six individual cultures. Data were analyzed by one-way ANOVA with Tukey's post hoc test. The dashed lines in $\mathbf{b}$ and $\mathbf{c}$ indicate expression levels in unstimulated (control) microglia. Comparisons are as follows: asterisk differences from control microglia, dagger sign CTL versus different activation states in the presence of myelin, number sign effects of myelin within a particular activation state (a) or effects of a second stimulus on the first stimulus (b and $\mathbf{c}$ ). One symbol $p<0.05$, two symbols $p<0.01$, three symbols $p<0.001$

SIRP $\alpha$ signal and a known increase in the ability of CR3 to bind targets under pro-inflammatory conditions [74]. Despite the increase in FcyRIIIa, it is not likely involved. It binds to the Fc component of antibodies but antibody-mediated opsonization of the myelin debris should not occur because the culture medium contained heat-inactivated serum. (ii) For M2 stimulation, published data on phagocytosis-related receptors are very 


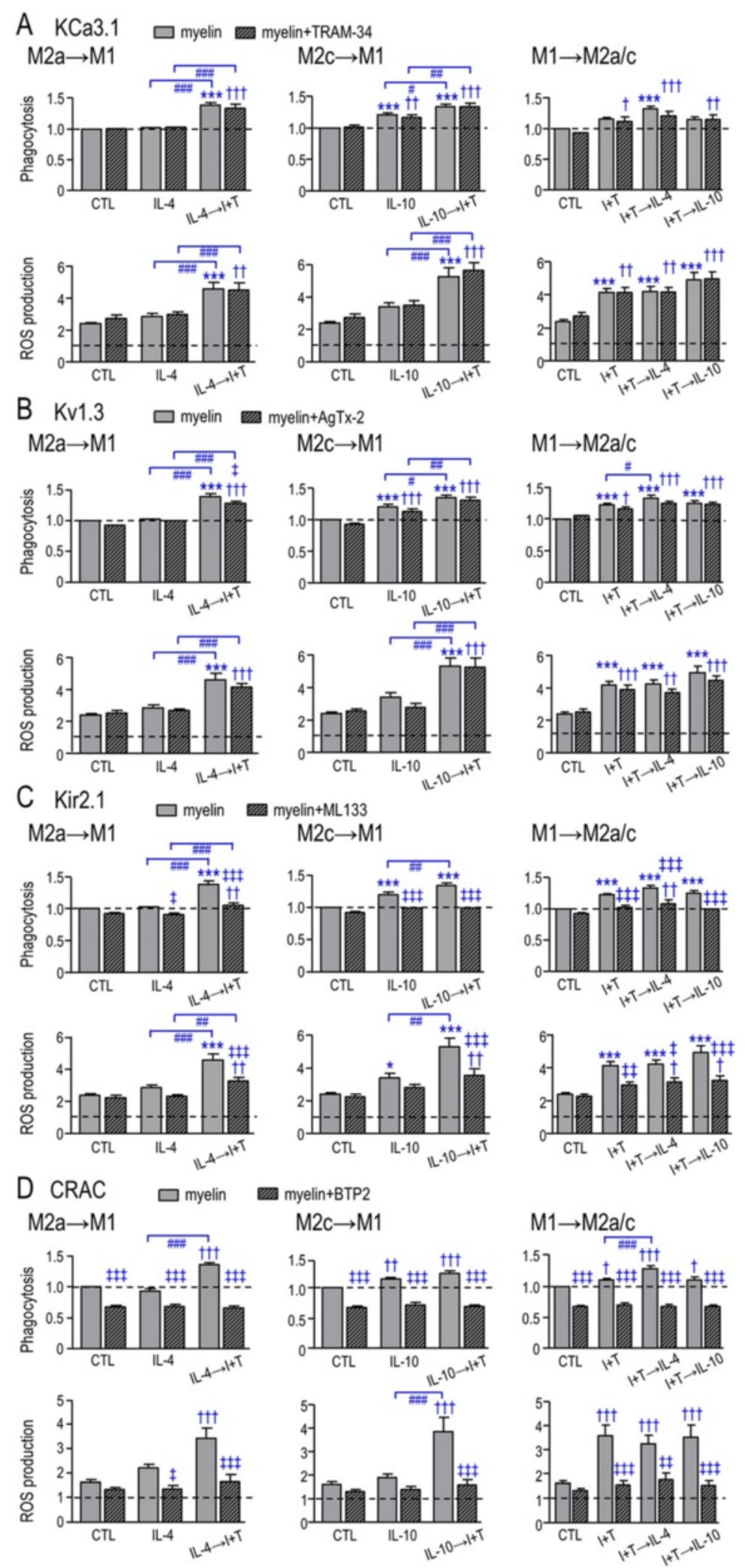

Fig. 9 (See legend on next page.) 
(See figure on previous page.)

Fig. 9 Roles of $\mathrm{K}^{+}$and CRAC channels in myelin phagocytosis and ROS production. Microglia were stimulated for $24 \mathrm{~h}$ (as in Fig. 8), and then a channel blocker was added with or without myelin for a further $6 \mathrm{~h}$. The panels show single stimuli, as well as M2a $\rightarrow \mathrm{M} 1$ (left), M2c $\rightarrow \mathrm{M} 1$ (middle), and both $\mathrm{M} 1 \rightarrow \mathrm{M} 2 \mathrm{a}$ and $\mathrm{M} 1 \rightarrow \mathrm{M} 2 \mathrm{C}$ (right). a KCa3.1 inhibition using $1 \mu \mathrm{M}$ TRAM-34. b Kv1.3 inhibition using 5 nM Agitoxin-2 (AgTx-2). c Kir2.1 inhibition using $20 \mu \mathrm{M}$ ML133. d CRAC inhibition using $10 \mu \mathrm{M}$ BTP2. Graphical data are expressed as mean \pm SEM ( $n=6$ individual cultures) and were analyzed by a two-way ANOVA with Bonferroni's post hoc test. The dashed lines indicate levels in unstimulated microglia with myelin. Comparisons are as follows: asterisk differences from control microglia, dagger sign CTL versus activation states in the presence of a channel inhibitor, number sign effect of a second stimulus on activated microglia, double dagger sign effect of a channel inhibitor within treatment group. One symbol $p<0.05$, two symbols $p<0.01$, three symbols $p<0.001$

limited and, again, there might be species differences. For rat microglia, we found that IL-4 treatment (M2a) increased expression of the inhibitory receptor, Fc $\gamma$ RIIb, and substantially decreased CD11b, SR-A, CD68, and TREM2 (no changes in SIRP $\alpha$, TIM-3). For murine microglia, IL-4 did not change FcyRIIb (CD32) expression [21]. Surprisingly, CD68 expression decreased in both M1 and M2a microglia and after myelin phagocytosis by unstimulated cells. CD68 is commonly used to identify activated, phagocytic microglia [7, 42-44]. Together, these results suggest that changes in receptor expression are not reliable predictors of the degree of myelin phagocytosis. Instead, protein levels and modulation might be more important. For instance, CR3 can potentiate or inhibit myelin phagocytosis depending on its conformation [32]. Although the changes we observed suggest a less phagocytic phenotype in the M2a state, myelin phagocytosis was comparable to untreated microglia. Of course, effects on phagocytosis of other targets after CNS damage (e.g., apoptotic neurons, cell debris, infiltrating blood cells) might differ by involving different receptors.

Phagocytosis is associated with elevated NOXmediated ROS production to help kill engulfed pathogens $[4,54]$. It was previously reported that untreated rat microglia robustly express the NOX2 isoform, with much lower NOX1 and NOX4 levels, and undetectable NOX3 [53]. Our results confirm this pattern and extend it to the M1 and M2a states. (i) Increased ROS production is a hallmark of M1 activation (reviewed in [20]), and we found that it was increased in I+T-treated microglia. NOX2 was likely responsible because expression of both NOX2 and its regulatory subunit, Ncf1, were increased to very high levels, while NOX1 and NOX4 remained at very low levels. (ii) IL-4 slightly increased ROS production while IL-10 had no effect, and this is consistent with our recent report [34]. IL-4 decreased expression of NOX2 and did not change Ncf1; however, both remained at moderate levels and could account for the ROS production.

\section{Effects of myelin phagocytosis}

There is some evidence that myelin phagocytosis can affect the M1 activation state. Effects are potentially time dependent, and negative self-regulation might protect the cells from "overeating" during extended exposures to targets [2]. When murine microglia were stimulated with IFN- $\gamma$ or LPS, a short exposure to myelin $(\leq 6 \mathrm{~h})$ exacerbated the pro-inflammatory response [10], while longer exposures $(16-24 \mathrm{~h})$ dampened this response $[10,75]$. Using the short exposure time (6 h), which was sufficient for optimal myelin uptake (see the "Methods" section); we found little effect on the molecular profile of unstimulated rat microglia. In contrast, myelin increased expression of pro-inflammatory cytokines in M1 (I+Ttreated) rat microglia. This is consistent with the previous short exposure study [10]. In IL-4-treated cells, myelin reduced several M2a-associated molecules. These results suggest that myelin can skew activated rat microglia toward a pro-inflammatory state.

Because levels of phagocytosis-related receptors were not well predicted by the microglial activation state (above); it was important to ask whether they were altered by exposure to myelin debris. In unstimulated microglia, myelin slightly decreased SIRP $\alpha$ and considerably increased $C X_{3} C R 1$ and $P_{2} Y_{6}$, which are all expected to promote phagocytosis, especially of apoptotic cells. (i) In I + T-treated (M1) cells, myelin did not alter expression of receptors known to be involved in myelin phagocytosis (CD11b, SR-A, TREM2, CX 3 CR1, SIRP $\alpha$ ). Instead, it increased $\mathrm{P}_{2} \mathrm{Y}_{6}, \mathrm{Fc} \gamma \mathrm{RIII}, \mathrm{C} 1 \mathrm{r}$, and TIM-3 and slightly decreased FcyRIIb, changes that could promote phagocytosis of other targets. (ii) In IL-4-treated (M2a) cells, myelin greatly increased $\mathrm{CX}_{3} \mathrm{CR} 1$ and slightly increased $\mathrm{P}_{2} \mathrm{Y}_{6}$. CD68 was slightly decreased, and CD11b or SR-A were unchanged. Interestingly, $\mathrm{CX}_{3} \mathrm{CR} 1$ [76] and $\mathrm{P}_{2} \mathrm{Y}_{6}$ [7] promote microglial migration toward damaged cells, and we previously found that M2a-activated rat microglia migrate better [25]. Thus, exposure to myelin debris might further potentiate the migratory capacity of M2a-activated microglia.

Myelin phagocytosis increases ROS production by unstimulated microglia [10, 22]. We confirmed this and showed that the myelin-evoked ROS production required NOX activity under all activation conditions tested (I + T, IL-4, IL-10). Myelin did not affect expression of NOX enzymes, but it increased expression of the proton channel, Hv1, which could contribute to the 
increased ROS production seen in unstimulated and M1activated cells. Moreover, myelin binding to Mac1 (CD11b) can activate NOX2 and promote ROS generation [77]. Interestingly, inhibiting NOX activity reduced myelin phagocytosis under all activation conditions tested. While we do not know the mechanism, an earlier study of rat macrophages suggested that NOX-mediated ROS production promotes signaling mechanisms involved in myelin phagocytosis [78].

\section{Sequential cytokine stimulation}

After acute CNS injury, the inflammatory milieu changes over time $[79,80]$. However, whether microglial activation states are functionally plastic is poorly understood. It is important to determine if, once polarized, they can respond to new signals. Based on the few studies that have addressed time-dependent changes in the overall inflammatory state in vivo, the outcome might depend on the type of injury. In the cuprizone-induced demyelination model, an overall M1 state gave way to an M2a phenotype at the time of re-myelination [68]. In the first week after intracerebral hemorrhage, we observed concurrent elevation of pro- and antiinflammatory mediators [81, 82]. However, after cerebral ischemia or traumatic brain injury, murine microglia exhibited an early M2 state, followed by M1 [67, 83]. An in vitro study of rat microglia found that adding IL-4 (M2a) before LPS (M1) decreased expression of the M1associated molecules, COX-2, iNOS, and TNF- $\alpha$ compared with LPS alone [84]. Similarly, in mixed rat glial cell cultures, simultaneous addition of LPS and IL-4 (or IL-10; M2c) reduced IL- 6 , TNF- $\alpha$, and NO production, compared with LPS alone [85]. Both studies assessed pro-inflammatory mediators only. For murine microglia, when LPS was followed by IL-4, NOS2 and COX-2 expression decreased, while CD206 (MRC1) and Arginase 1 (M2a markers) increased compared with LPS alone $[21,86]$. The present study greatly extends these previous reports.

We examined effects of sequential addition of M1and M2-inducing cytokines on the inflammatory profile, expression of phagocytosis-related receptors and ROSrelated molecules, and on myelin phagocytosis and consequent ROS production. We employed four sequential treatment paradigms that address the possibility that the cytokine profile changes after injury or disease. The most convincing re-polarization of the inflammatory state was between I $+\mathrm{T}$ and IL- 4 treatments, applied in both sequences. (i) M1 $\rightarrow$ M2a paradigm: In I + T-primed microglia, adding IL-4 dampened the pro-inflammatory profile (NOS2, TNF- $\alpha$, IL-6, COX-2) and increased M2a markers (MRC1, c-myc, CCL22). This is entirely consistent with previous studies using LPS and IL-4 (cited above). The relationship of phagocytosis and ROS production to expression of receptors and enzymes and to phagocytosis- and ROS-related molecules was complicated and, sometimes, unexpected. Although myelin phagocytosis was increased, several phagocytosispromoting receptors decreased (CD11b, Fc $\gamma$ RIIIa, CD68, C1r, TIM-3), compared with I $+\mathrm{T}$ alone. Among the inhibitory receptors, SIRP $\alpha$ decreased and Fc $\gamma$ RIIb was unchanged. Thus, the decrease in SIRP $\alpha$ might have promoted phagocytosis. Despite the lack of change in ROS production, ROS-related molecules decreased (NOX enzymes, Ncf1, Hv1), suggesting that the remaining levels were sufficient. (ii) M2a $\rightarrow$ M1: In IL-4treated cells, adding $\mathrm{I}+\mathrm{T}$ skewed them toward an M1 profile. There was increased expression of most pro-inflammatory molecules (NOS2, TNF- $\alpha$, COX-2), decreases in some M2 markers (MRC1, CD163), and increased myelin phagocytosis and ROS production. The outcome might depend on the exact stimulus paradigm and target type. For instance, we observed some changes in receptor expression that are expected to promote phagocytosis: an increase in $\mathrm{P}_{2} \mathrm{Y}_{6}$ and decreases in the inhibitory receptors, FcyRIIb and SIRP $\alpha$. Most phagocytosis-promoting receptors decreased, particularly CD11b, TREM2, CD68, TIM3, and $\mathrm{CX}_{3} \mathrm{CR} 1$. (iii) $\mathrm{M} 1 \rightarrow \mathrm{M} 2 \mathrm{c}$ : In I + T-primed cells, adding IL-10 did not resolve the pro-inflammatory state and, surprisingly, it increased iNOS/NOS2 expression. While expression of several phagocytosis-related receptors increased (CD11b, Fc $\gamma$ RIIIa, TIM-3), SIRP $\alpha$ increased slightly, while phagocytosis and ROS production were unchanged. (iv) $\mathrm{M} 2 \mathrm{c} \rightarrow \mathrm{M} 1:$ In IL-10-treated cells, adding $\mathrm{I}+\mathrm{T}$ increased myelin phagocytosis and ROS production (gene changes were not examined, as explained above).

Overall, our results show malleability in re-polarization of rat microglia between M1 and M2a states. Their qualitative ability to respond to a new incoming signal was preserved but their quantitative response was often reduced. The amount of re-polarization could well depend on the experimental paradigm (cytokine concentrations, time course). For instance, although we did not observe resolution of M1 activation by IL-10, it is possible that the time course of treatment or monitoring was not optimal. In the future, in vivo spatial and temporal changes in the cytokine environment will need to be examined in each damage/disease model to further examine the repolarization capacity of microglia.

\section{Expression and contributions of ion channels}

Ion channels regulate numerous processes in cells that are relevant to phagocytosis, including cell volume, $\mathrm{Ca}^{2+}$ signaling, and cytoskeletal re-organization [87]. Microglia express a surprisingly large array of ion channels, some of which are involved in proliferation, migration, 
and $\mathrm{Ca}^{2+}$ signaling (reviewed in $[42,88]$ ). Very little is known about roles of channels in phagocytosis by microglia; particularly in different activation states. We previously found that $\mathrm{Cl}^{-}$channels regulate phagocytosis of E. coli by rat microglia [65]. Phagocytosis is a $\mathrm{Ca}^{2+}$-dependent process that involves SOCE $[89,90]$. The CRAC channel is apparently the major SOCE pathway in rat microglia [33, 35, 91, 92]. Interestingly, $C R A C$ can be activated by $\mathrm{P}_{2} \mathrm{Y}_{6}$ and other $\mathrm{G}$ protein-coupled metabotropic receptors, and we found that phagocytosis of myelin debris increased $\mathrm{P}_{2} \mathrm{Y}_{6}$ expression under all activation states examined. We then focused on CRAC and three $\mathrm{K}^{+}$channels (KCa3.1, Kir2.1, Kv1.3) that are thought or known to regulate $\mathrm{Ca}^{2+}$ entry. In rat microglia, KCa3.1 and Kir2.1 regulate CRAC-mediated $\mathrm{Ca}^{2+}$ influx [24, 33, 35], and Kv1.3 is involved in ROS production [14, 37]. CRAC channels are comprised of a pore-forming Orail subunit and $\mathrm{Ca}^{2+}$-sensing STIM1 subunit [64]. While other subunits are considered less important, SOCE in murine microglia might also involve STIM2 [90], and Orai3 activity can also be regulated by STIM proteins [64]. Rodent microglia express mRNA for Orai1, Orai3, STIM1, and STIM2 [89-91]. In murine microglia, Orai1, STIM1, and STIM2 contribute to SOCE and phagocytosis [89, 90]. There are few reports regarding changes in $\mathrm{Ca}^{2+}$ signaling and expression of relevant $\mathrm{Ca}^{2+}$-signaling molecules in specific activation states; and the results are somewhat inconsistent. For murine microglia, LPS (M1) increased STIM1 without affecting Orai1 or Orai3 in one study [89], but reduced STIM1 and Orai3 without affecting Orai1 or STIM2 in another [90]. Orail expression was not changed in either study but SOCE was reduced. The $\mathrm{Ca}^{2+}$ entry pathway was not determined. An earlier study of murine microglia reported that LPS rapidly elevated basal $\mathrm{Ca}^{2+}$ and reduced the UTP-induced rise [93]. For human microglia, M1 stimulation (GM-CSF + LPS + IFN- $\gamma$ ) did not affect the $\mathrm{Ca}^{2+}$ response to ADP; whereas, M2 activation (M-CSF + IL-4 + IL-13) increased it and this was attributed to increased $\mathrm{P}_{2} \mathrm{Y}_{12}$ receptor expression [94]. For rat microglia, we recently found that the CRAC-mediated $\mathrm{Ca}^{2+}$ rise was $\sim 50 \%$ lower after IL-4 treatment (M2a) but not affected by IL-10 (M2c) [35].

In unstimulated rat microglia, myelin affected expression of Kv1.3 only (increased) but channel expression was strongly affected by the microglial activation state. (i) I + T-treated (M1) cells had increased expression of Kv1.3, KCa3.1, Kir2.1, STIM1, STIM2, and Orai3. Myelin phagocytosis increased Kv1.3, KCa3.1, Orai1, and Orai3. The high STIM expression and increase in Orail, the pore-forming subunit of CRAC, should facilitate $\mathrm{Ca}^{2+}$ signaling. (ii) IL-4-treated (M2a) cells had increased Kv1.3 and KCa3.1 compared with control cells. Myelin had no further effects. No Orai or STIM molecules increased but STIM2 decreased slightly. Thus, the previously observed decrease in CRAC signaling [35] is not readily explained by Orai or STIM expression. (iii) Sequential cytokine addition had complex effects on channel expression. M1 $\rightarrow$ M2a: Compared with $\mathrm{I}+\mathrm{T}$ stimulation alone, subsequent IL-4 addition reduced KCa3.1, Kv1.3, Kir2.1, Orai3, STIM1, and STIM2. $\mathrm{M} 2 \mathrm{a} \rightarrow \mathrm{M} 1$ : Compared with IL-4 alone, subsequent I + T addition decreased expression of KCa3.1, Kv1.3, Orai3, STIM1, and STIM2, but not Kir2.1. M1 $\rightarrow$ M2c: Compared with $\mathrm{I}+\mathrm{T}$ alone, subsequent addition of IL-10 only changed KCa3.1, which was increased. Overall, with respect to ion channels, rat microglia showed considerable re-polarization between M1 and M2a states, while IL-10 was ineffective.

The use of selective channel blockers showed that CRAC was important for phagocytosis under all activation conditions examined, while myelin phagocytosis and ROS production by activated microglia were both dependent on Kir2.1 (but not Kv1.3 or KCa3.1). What could account for a lack of contribution of Kv1.3 and $\mathrm{KCa} 3.1$ when, in principle, all routes of $\mathrm{K}^{+}$flux can control the membrane potential of cells? The simplest possibility is that, despite substantial transcript expression, Kv1.3 and KCa3.1 were not active during myelin phagocytosis. We propose a scenario in which Kv1.3 and KCa3.1 are inhibited, while Kir2.1 and CRAC are facilitated. All three $\mathrm{K}^{+}$channels are post-translationally regulated by signaling molecules downstream of the phagocytosis receptors, CR3 and SR-A. CR3 signaling activates Src family tyrosine kinases, phosphoinositide-3kinase (PI3K) and phospholipase C (PLC) [74, 95]. Kv1.3 is strongly inhibited by activated $\mathrm{Src}$ in rat microglia [36]. Lipid phosphatases localize to phagosome cups (see reviews [55, 74]), and the lipid phosphatase, myotubularin-related protein 6 (MTMR6) regulates macropinocytosis [96], which uses similar machinery to phagocytosis [97]. KCa3.1 is strongly inhibited by MTMR6 [98]. How might Kir2.1 and CRAC channel activity be promoted? Both CR3 and SR-A signaling involve PLC [99] and PI3K [100]. PI3K generates PIP2, which stabilizes the open configuration of Kir2.1 channels [101]. PLC activity generates diacylglycerol (DAG) and inositol triphosphate $\left(\mathrm{IP}_{3}\right)$, which depletes $\mathrm{ER}$ calcium stores and activates CRAC channels [55]. In addition, DAG activates protein kinase $\mathrm{C}$, which can stimulate NOX enzymes and increase ROS production [54].

\section{Conclusions}

Experimental strategies for treating acute CNS injury increasingly address inflammation, often targeting proor anti-inflammatory states in a generalized manner. Some preclinical studies target innate immune cells 
(microglia, macrophages, neutrophils) more selectively, but it is crucial to investigate potential targets in different cell activation states. Further specificity in target selection will be necessary because some products and functions can be either detrimental or beneficial, as is the case for phagocytosis. In CNS disease and injury states where white matter is damaged, efficient remyelination requires that microglia remove myelin debris from affected axons. Therefore, treatment strategies should preserve microglial phagocytosis while reducing harmful inflammatory responses.

Here, we investigated numerous molecular and functional changes in rat microglia skewed to different M1 and M2 activation states. Our results illustrate several complex outcomes that should be considered in pursuing strategies to target microglia. For instance, the M1 state increased phagocytosis of myelin debris, which could aid in tissue repair, but NOX-mediated ROS production was also increased, which might damage bystander cells. Myelin phagocytosis exacerbated M1 activation, decreased M2 activation, and evoked more NOX-mediated ROS production, suggesting a positivefeedback network that might increase damage. Using sequential cytokine addition to model changing activation cues after acute CNS injury, we asked whether microglia can be re-polarized from one activation state to another. Qualitative molecular re-polarization was seen between M1 and M2a states with the paradigms used, which supports attempts to re-program the inflammatory response in vivo. Moreover, because both $\mathrm{M} 1 \rightarrow \mathrm{M} 2$ and $\mathrm{M} 2 \rightarrow \mathrm{M} 1$ paradigms increased myelin phagocytosis, it might be possible to maintain efficient debris clearance while therapeutically altering inflammatory mediators to a less toxic mix.

Ion channels are increasingly proposed as molecular targets for controlling CNS inflammation. This study contributes information about channel expression and functional contributions that should be taken into account. While Kv1.3 and KCa3.1 expression were affected by the microglial activation state, neither channel contributed to myelin phagocytosis. Thus, Kv1.3 and KCa3.1 blockers might be useful for reducing inflammation without preventing beneficial debris clearance. On the other hand, Kir2.1 and CRAC channels facilitated myelin phagocytosis in all activated states, suggesting that stimulating their activity might aid in debris clearance. However, our results also suggest that facilitating these channels will also increase ROS production whenever an M1 stimulus is present, and this could damage bystander cells.

This study greatly extends our knowledge by examining effects of single versus sequential addition of M1and M2-inducing cytokines. Results on myelin phagocytosis and consequent ROS production are most relevant to diseases involving white matter damage, such as spinal cord injury, stroke, hemorrhage, brain trauma, MS, and ALS. However, results concerning the inflammatory profile, expression of phagocytosis-related receptors, ROS-related molecules, and ion channels will be broadly applicable to CNS injury and disease.

\section{Abbreviations \\ CD: cluster of differentiation; CNS: central nervous system; CR3: complement receptor 3; CRAC: calcium release activated calcium; DAG: diacylglycerol; DCF: dichlorodihydrofluorescein; Dil: 1,1'-dioctadecyl-3,3,3',3'- \\ tetramethylindocarbocyanine perchlorate; FBS: fetal bovine serum; HEPES: 4-(2-hydroxyethyl)-1-piperazineethanesulfonic acid; IFN- $\gamma$ : interferon gamma; IL: interleukin; IP: inositol trisphosphate; LAMP-1: lysosome-associated membrane glycoprotein-1; LPS: lipopolysaccharide; MEM: minimum essential medium; MTMR6: myotubularin related protein 6; NADPH: nicotinamide adenine dinucleotide phosphate; NOX: NADPH oxidase; PI3K: phosphoinositide- 3-kinase; PIP2: phosphotidylinositol bisphosphate; PLC: phospholipase C; PMA: phorbol myristate acetate; RNA: ribonucleic acid; ROS: reactive oxygen species; RT-PCR: reverse transcription-polymerase chain reaction; SIRPa: signal regulatory protein alpha; SOCE: store operated calcium entry; SR-A: scavenger receptor-A; STIM: stromal interaction molecule; TIM-3: T-cell immunoglobulin and mucin-domain containing 3; TNF-a: tumor necrosis factor alpha; \\ TREM2: triggering receptor expressed on myeloid cells 2.}

\section{Competing interests}

The authors declare that they have no competing interests.

\section{Authors' contributions}

TAS performed immunocytochemistry and acquired and analyzed all data regarding phagocytosis and ROS (Figs. 1, 2, 3, 7, 8, and 9). SL carried out and analyzed the Nanostring data (Figs. 1, 2, 3, 4, 5, and 6). LCS, TAS, and SL conceived and designed the project, and LCS supervised the work. TAS and SL helped LCS prepare the manuscript. All authors have read and approved the final manuscript.

\section{Acknowledgements}

The authors thank Xiaoping Zhu and Raymond Wong for preparing mixed glial cell cultures for microglia isolation. The work was supported by grants to LCS from the Canadian Institutes for Health Research (MOP 119578), the Heart and Stroke Foundation of Canada (00493), and by the Toronto General/Toronto Western Research Foundation.

\section{Author details}

'Genes and Development Division, Krembil Research Institute, University Health Network, Toronto, Ontario M5T 2S8, Canada. ${ }^{2}$ Department of Physiology, University of Toronto, Toronto, Ontario, Canada. ${ }^{3}$ Krembil Discovery Tower, Krembil Research Institute, Room 7KD-417, 60 Leonard Street, Toronto, Ontario M5T 258, Canada.

Received: 8 February 2016 Accepted: 16 March 2016

Published online: 24 March 2016

\section{References}

1. Gitik M, Liraz-Zaltsman S, Oldenborg PA, Reichert F, Rotshenker S. Myelin down-regulates myelin phagocytosis by microglia and macrophages through interactions between CD47 on myelin and SIRPalpha (signal regulatory protein-alpha) on phagocytes. J Neuroinflammation. 2011;8:24.

2. Hadas S, Spira M, Hanisch UK, Reichert F, Rotshenker S. Complement receptor-3 negatively regulates the phagocytosis of degenerated myelin through tyrosine kinase Syk and cofilin. J Neuroinflammation. 2012;9:166

3. Sierra A, Abiega O, Shahraz A, Neumann H. Janus-faced microglia: beneficial and detrimental consequences of microglial phagocytosis. Front Cell Neurosci. 2013;7:6.

4. Bedard K, Krause KH. The NOX family of ROS-generating NADPH oxidases: physiology and pathophysiology. Physiol Rev. 2007;87:245-313.

5. Block ML, Zecca L, Hong JS. Microglia-mediated neurotoxicity: uncovering the molecular mechanisms. Nat Rev Neurosci. 2007;8:57-69. 
6. Brown GC, Neher JJ. Microglial phagocytosis of live neurons. Nat Rev Neurosci. 2014;15:209-16.

7. Fu R, Shen Q, Xu P, Luo JJ, Tang Y. Phagocytosis of microglia in the central nervous system diseases. Mol Neurobiol. 2014;49:1422-34.

8. Surace MJ, Block ML. Targeting microglia-mediated neurotoxicity: the potential of NOX2 inhibitors. Cell Mol Life Sci. 2012;69:2409-27.

9. Tremblay ME, Stevens B, Sierra A, Wake H, Bessis A, Nimmerjahn A. The role of microglia in the healthy brain. J Neurosci. 2011;31:16064-9.

10. Liu Y, Hao W, Letiembre M, Walter S, Kulanga M, Neumann H,Fassbender K. Suppression of microglial inflammatory activity by myelin phagocytosis: role of p47-PHOX-mediated generation of reactive oxygen species. J Neurosci. 2006;26:12904-13.

11. Newell EW, Stanley EF, Schlichter LC. Reversed $\mathrm{Na}^{+} / \mathrm{Ca}^{2+}$ exchange contributes to $\mathrm{Ca}^{2+}$ influx and respiratory burst in microglia. Channels. 2007;1:366-76.

12. Williams K, Ulvestad E, Waage A, Antel JP, McLaurin J. Activation of adult human derived microglia by myelin phagocytosis in vitro. J Neurosci Res. 1994;38:433-43.

13. Cheret C, Gervais A, Lelli A, Colin C, Amar L, Ravassard P, Mallet J, Cumano A, Krause $\mathrm{KH}$, Mallat M. Neurotoxic activation of microglia is promoted by a nox1-dependent NADPH oxidase. J Neurosci. 2008;28:12039-51.

14. Fordyce CB, Jagasia R, Zhu X, Schlichter LC. Microglia Kv1.3 channels contribute to their ability to kill neurons. J Neurosci. 2005;25:7139-49.

15. Kaushal V, Koeberle PD, Wang Y, Schlichter LC. The $\mathrm{Ca}^{2+}$-activated $\mathrm{K}^{+}$ channel KCNN4/KCa3.1 contributes to microglia activation and nitric oxide-dependent neurodegeneration. J Neurosci. 2007;27:234-44.

16. Qin L, Liu Y, Wang T, Wei SJ, Block ML, Wilson B, Liu B, Hong JS. NADPH oxidase mediates lipopolysaccharide-induced neurotoxicity and proinflammatory gene expression in activated microglia. J Biol Chem. 2004; 279:1415-21.

17. Cherry JD, Olschowka JA, O'Banion MK. Neuroinflammation and M2 microglia: the good, the bad, and the inflamed. J Neuroinflammation. 2014;11:98.

18. Colton CA. Heterogeneity of microglial activation in the innate immune response in the brain. J Neuroimmune Pharmacol. 2009:4:399-418.

19. Franco R, Fernandez-Suarez D. Alternatively activated microglia and macrophages in the central nervous system. Prog Neurobiol. 2015;131:65-86.

20. Hanisch UK. Functional diversity of microglia-how heterogeneous are they to begin with? Front Cell Neurosci. 2013;7:65.

21. Chhor V, Le Charpentier T, Lebon S, Ore MV, Celador IL, Josserand J, Degos V, Jacotot E, Hagberg H, Savman K, et al. Characterization of phenotype markers and neuronotoxic potential of polarised primary microglia in vitro. Brain Behav Immun. 2013;32:70-85.

22. Smith ME, van der Maesen K, Somera FP. Macrophage and microglial responses to cytokines in vitro: phagocytic activity, proteolytic enzyme release, and free radical production. J Neurosci Res. 1998;54:68-78.

23. Durafourt BA, Moore CS, Zammit DA, Johnson TA, Zaguia F, Guiot MC, BarOr A, Antel JP. Comparison of polarization properties of human adult microglia and blood-derived macrophages. Glia. 2012;60:717-27.

24. Ferreira R, Lively S, Schlichter LC. IL-4 type 1 receptor signaling upregulates KCNN4 expression, and increases the KCa3.1 current and its contribution to migration of alternative-activated microglia. Front Cell Neurosci. 2014:8:183.

25. Lively S, Schlichter LC. The microglial activation state regulates migration and roles of matrix-dissolving enzymes for invasion. J Neuroinflammation. 2013;10:75.

26. Siddiqui T, Lively S, Ferreira R, Wong R, Schlichter LC. Expression and contributions of TRPM7 and KCa2.3/SK3 channels to the increased migration and invasion of microglia in anti-inflammatory activation states. PLoS One. 2014;9:e106087.

27. Wong R, Schlichter LC. PKA reduces the rat and human KCa3.1 current, CaM binding, and $\mathrm{Ca}^{2+}$ signaling, which requires Ser332/334 in the CaM-binding C terminus. J Neurosci. 2014;34:13371-83.

28. Geiss GK, Bumgarner RE, Birditt B, Dahl T, Dowidar N, Dunaway DL, Fell HP, Ferree S, George RD, Grogan T, et al. Direct multiplexed measurement of gene expression with color-coded probe pairs. Nat Biotechnol. 2008;26:317-25.

29. Sivagnanam V, Zhu X, Schlichter LC. Dominance of E. coli phagocytosis over LPS in the inflammatory response of microglia. J Neuroimmunol. 2010;227:111-9.

30. Norton WT, Poduslo SE. Myelination in rat brain: method of myelin isolation. J Neurochem. 1973;21:749-57.
31. Greenhalgh AD, David S. Differences in the phagocytic response of microglia and peripheral macrophages after spinal cord injury and its effects on cell death. J Neurosci. 2014;34:6316-22.

32. Reichert F, Slobodov U, Makranz C, Rotshenker S. Modulation (inhibition and augmentation) of complement receptor-3-mediated myelin phagocytosis. Neurobiol Dis. 2001:8:504-12.

33. Ferreira R, Schlichter LC. Selective activation of KCa3.1 and CRAC channels by P2Y2 receptors promotes $\mathrm{Ca}^{2+}$ signaling, store refilling and migration of rat microglial cells. PLoS One. 2013;8:e62345.

34. Ferreira $R$, Wong $R$, Schlichter LC. KCa3.1/K1 channel regulation by cGMPdependent protein kinase (PKG) via reactive oxygen species and CaMKII in microglia: an immune modulating feedback system? Front Immunol. 2015;6:153.

35. Lam D, Schlichter LC. Expression and contributions of the Kir2.1 inward-rectifier $\mathrm{K}^{+}$channel to proliferation, migration and chemotaxis of microglia in unstimulated and anti-inflammatory states. Front Cell Neurosci. 2015;9:185.

36. Cayabyab FS, Khanna R, Jones OT, Schlichter LC. Suppression of the rat microglia Kv1.3 current by src-family tyrosine kinases and oxygen/glucose deprivation. Eur J Neurosci. 2000;12:1949-60.

37. Khanna R, Roy L, Zhu X, Schlichter LC. $K^{+}$channels and the microglial respiratory burst. Am J Physiol Cell Physiol. 2001;280:C796-806.

38. Newell EW, Schlichter LC. Integration of $\mathrm{K}^{+}$and $\mathrm{Cl}^{-}$currents regulate steadystate and dynamic membrane potentials in cultured rat microglia. J Physiol. 2005;567:869-90.

39. Liu BS, Ferreira R, Lively S, Schlichter LC. Microglial SK3 and SK4 currents and activation state are modulated by the neuroprotective drug, riluzole. J Neuroimmune Pharmacol. 2013;8:227-37.

40. Smith ME. Phagocytic properties of microglia in vitro: implications for a role in multiple sclerosis and EAE. Microsc Res Tech. 2001;54:81-94.

41. Linnartz B, Wang Y, Neumann H. Microglial immunoreceptor tyrosine-based activation and inhibition motif signaling in neuroinflammation. Int J Alzheimers Dis. 2010;2010:587463.

42. Kettenmann H, Hanisch UK, Noda M, Verkhratsky A. Physiology of microglia. Physiol Rev. 2011;91:461-553.

43. Schlichter L, Hutchings $\mathrm{S}$, Lively $\mathrm{S}$. Inflammation and white matter injury in animal models of ischemic stroke. In: Baltan S, Carmichael ST, Matute C, Xi G, Zhang JH, editors. White matter injury in stroke and CNS disease. 2014. p. 461-504.

44. Taylor RA, Sansing LH. Microglial responses after ischemic stroke and intracerebral hemorrhage. Clin Dev Immunol. 2013;2013:746068.

45. Sarma JV, Ward PA. The complement system. Cell Tissue Res. 201 1;343:227-35.

46. Koizumi S, Shigemoto-Mogami Y, Nasu-Tada K, Shinozaki Y, Ohsawa K, Tsuda M, Joshi BV, Jacobson KA, Kohsaka S, Inoue K. UDP acting at P2Y6 receptors is a mediator of microglial phagocytosis. Nature. 2007;446:1091-5.

47. Poliani PL, Wang Y, Fontana E, Robinette ML, Yamanishi Y, Gilfillan S, Colonna M. TREM2 sustains microglial expansion during aging and response to demyelination. J Clin Invest. 2015;125:2161-70.

48. Cardona AE, Pioro EP, Sasse ME, Kostenko V, Cardona SM, Dijkstra IM, Huang D, Kidd G, Dombrowski S, Dutta R, et al. Control of microglial neurotoxicity by the fractalkine receptor. Nat Neurosci. 2006;9:917-24.

49. Lampron A, Larochelle A, Laflamme N, Prefontaine P, Plante MM, Sanchez MG, Yong WW, Stys PK, Tremblay ME, Rivest S. Inefficient clearance of myelin debris by microglia impairs remyelinating processes. J Exp Med. 2015;212: 481-95.

50. Anderson AC, Anderson DE, Bregoli L, Hastings WD, Kassam N, Lei C, Chandwaskar R, Karman J, Su EW, Hirashima M, et al. Promotion of tissue inflammation by the immune receptor Tim-3 expressed on innate immune cells. Science. 2007;318:1141-3.

51. Wang HW, Zhu XL, Qin LM, Qian HJ, Wang Y. Microglia activity modulated by T cell Ig and mucin domain protein 3 (Tim-3). Cell Immunol. 2015;293:49-58.

52. Cheng G, Cao Z, XU X, van Meir EG, Lambeth JD. Homologs of gp91 phox: cloning and tissue expression of Nox3, Nox4, and Nox5. Gene. 2001;269:131-40.

53. Harrigan TJ, Abdullaev IF, Jourd'heuil D, Mongin AA. Activation of microglia with zymosan promotes excitatory amino acid release via volume-regulated anion channels: the role of NADPH oxidases. J Neurochem. 2008:106:2449-62.

54. Brandes RP, Weissmann N, Schroder K. Nox family NADPH oxidases: molecular mechanisms of activation. Free Radic Biol Med. 2014:76:208-26.

55. Flannagan RS, Jaumouille V, Grinstein S. The cell biology of phagocytosis. Annu Rev Pathol. 2012;7:61-98,

56. Clark RA, Volpp BD, Leidal KG, Nauseef WM. Two cytosolic components of the human neutrophil respiratory burst oxidase translocate to the plasma membrane during cell activation. J Clin Invest. 1990;85:714-21. 
57. El-Benna J, Dang PM, Gougerot-Pocidalo MA, Marie JC, Braut-Boucher F. p47phox, the phagocyte NADPH oxidase/NOX2 organizer: structure, phosphorylation and implication in diseases. Exp Mol Med. 2009;41:217-25.

58. Martyn KD, Frederick LM, von Loehneysen K, Dinauer MC, Knaus UG. Functional analysis of Nox4 reveals unique characteristics compared to other NADPH oxidases. Cell Signal. 2006;18:69-82.

59. Serrander L, Cartier L, Bedard K, Banfi B, Lardy B, Plastre O, Sienkiewicz A, Forro L, Schlegel W, Krause KH. NOX4 activity is determined by mRNA levels and reveals a unique pattern of ROS generation. Biochem J. 2007;406:105-14.

60. Nayernia Z, Jaquet $\mathrm{V}$, Krause KH. New insights on NOX enzymes in the central nervous system. Antioxid Redox Signal. 2014;20:2815-37.

61. DeCoursey TE. Voltage-gated proton channels: molecular biology, physiology, and pathophysiology of the $H(V)$ family. Physiol Rev. 2013;93:599-652.

62. Ramsey IS, Ruchti E, Kaczmarek JS, Clapham DE. Hv1 proton channels are required for high-level NADPH oxidase-dependent superoxide production during the phagocyte respiratory burst. Proc Natl Acad Sci U S A. 2009; 106:7642-7.

63. Wind S, Beuerlein K, Eucker T, Muller H, Scheurer P, Armitage ME, Ho H, Schmidt HH, Wingler K. Comparative pharmacology of chemically distinct NADPH oxidase inhibitors. Br J Pharmacol. 2010;161:885-98.

64. Soboloff J, Rothberg BS, Madesh M, Gill DL. STIM proteins: dynamic calcium signal transducers. Nat Rev Mol Cell Biol. 2012;13:549-65.

65. Ducharme G, Newell EW, Pinto C, Schlichter LC. Small-conductance Cl channels contribute to volume regulation and phagocytosis in microglia. Eur J Neurosci. 2007;26:2119-30.

66. Zhao X, Wang H, Sun G, Zhang J, Edwards NJ, Aronowski J. Neuronal interleukin-4 as a modulator of microglial pathways and ischemic brain damage. J Neurosci. 2015;35:11281-91.

67. Hu X, Li P, Guo Y, Wang H, Leak RK, Chen S, Gao Y, Chen J. Microglia/ macrophage polarization dynamics reveal novel mechanism of injury expansion after focal cerebral ischemia. Stroke. 2012;43:3063-70.

68. Miron VE, Boyd A, Zhao JW, Yuen TJ, Ruckh JM, Shadrach JL, van Wijngaarden P, Wagers AJ, Williams A, Franklin RJ, ffrench-Constant C. M2 microglia and macrophages drive oligodendrocyte differentiation during CNS remyelination. Nat Neurosci. 2013;16:1211-8.

69. Hsieh CL, Koike M, Spusta SC, Niemi EC, Yenari M, Nakamura MC, Seaman WE. A role for TREM2 ligands in the phagocytosis of apoptotic neuronal cells by microglia. J Neurochem. 2009;109:1144-56.

70. Takahashi K, Rochford CD, Neumann H. Clearance of apoptotic neurons without inflammation by microglial triggering receptor expressed on myeloid cells-2. J Exp Med. 2005;201:647-57.

71. Schmid CD, Sautkulis LN, Danielson PE, Cooper J, Hasel KW, Hilbush BS, Sutcliffe JG, Carson MJ. Heterogeneous expression of the triggering receptor expressed on myeloid cells-2 on adult murine microglia. J Neurochem. 2002;83:1309-20.

72. Noda M, Doi Y, Liang J, Kawanokuchi J, Sonobe Y, Takeuchi H, Mizuno T, Suzumura A. Fractalkine attenuates excito-neurotoxicity via microglial clearance of damaged neurons and antioxidant enzyme heme oxygenase-1 expression. J Biol Chem. 2011;286:2308-19.

73. Boddeke EW, Meigel I, Frentzel S, Biber K, Renn LQ, Gebicke-Harter P. Functional expression of the fractalkine $\left(\mathrm{CX}_{3} \mathrm{C}\right)$ receptor and its regulation by lipopolysaccharide in rat microglia. Eur J Pharmacol. 1999;374:309-13.

74. Freeman SA, Grinstein S. Phagocytosis: receptors, signal integration, and the cytoskeleton. Immunol Rev. 2014;262:193-215.

75. Kroner A, Greenhalgh AD, Zarruk JG, Passos Dos Santos R, Gaestel M, David S. TNF and increased intracellular iron alter macrophage polarization to a detrimental M1 phenotype in the injured spinal cord. Neuron. 2014;83: 1098-116.

76. Arnoux I, Audinat E. Fractalkine signaling and microglia functions in the developing brain. Neural Plast. 2015;2015:689404.

77. Chen SH, Oyarzabal EA, Hong JS. Critical role of the Mac1/NOX2 pathway in mediating reactive microgliosis-generated chronic neuroinflammation and progressive neurodegeneration. Curr Opin Pharmacol. 2015;26:54-60.

78. van der Goes A, Brouwer J, Hoekstra K, Roos D, van den Berg TK, Dijkstra CD. Reactive oxygen species are required for the phagocytosis of myelin by macrophages. J Neuroimmunol. 1998;92:67-75.

79. Hanisch UK, Kettenmann H. Microglia: active sensor and versatile effector cells in the normal and pathologic brain. Nat Neurosci. 2007;10:1387-94.

80. Prinz M, Priller J. Microglia and brain macrophages in the molecular age: from origin to neuropsychiatric disease. Nat Rev Neurosci. 2014;15:300-12.
81. Lively S, Schlichter LC. Age-related comparisons of evolution of the inflammatory response after intracerebral hemorrhage in rats. Transl Stroke Res. 2012;3:132-46.

82. Wasserman JK, Zhu X, Schlichter LC. Evolution of the inflammatory response in the brain following intracerebral hemorrhage and effects of delayed minocycline treatment. Brain Res. 2007;1180:140-54.

83. Wang G, Zhang J, Hu X, Zhang L, Mao L, Jiang X, Liou AK, Leak RK, Gao Y, Chen J. Microglia/macrophage polarization dynamics in white matter after traumatic brain injury. J Cereb Blood Flow Metab. 2013;33:1864-74.

84. Kitamura Y, Taniguchi T, Kimura H, Nomura Y, Gebicke-Haerter PJ. Interleukin-4-inhibited mRNA expression in mixed rat glial and in isolated microglial cultures. J Neuroimmunol. 2000;106:95-104.

85. Ledeboer A, Breve JJ, Poole S, Tilders FJ, Van Dam AM. Interleukin-10, interleukin-4, and transforming growth factor-beta differentially regulate lipopolysaccharide-induced production of pro-inflammatory cytokines and nitric oxide in co-cultures of rat astroglial and microglial cells. Glia. 2000;30:134-42.

86. Fenn AM, Henry CJ, Huang Y, Dugan A, Godbout JP. Lipopolysaccharideinduced interleukin (IL)-4 receptor-alpha expression and corresponding sensitivity to the $M 2$ promoting effects of IL-4 are impaired in microglia of aged mice. Brain Behav Immun. 2012;26:766-77.

87. Schwab A, Fabian A, Hanley PJ, Stock C. Role of ion channels and transporters in cell migration. Physiol Rev. 2012;92:1865-913.

88. Stebbing MJ, Cottee JM, Rana I. The role of ion channels in microglial activation and proliferation - a complex interplay between ligand-gated ion channels, $\mathrm{K}^{+}$channels, and intracellular $\mathrm{Ca}^{2+}$. Front Immunol. 2015;6:497.

89. Heo DK, Lim HM, Nam JH, Lee MG, Kim JY. Regulation of phagocytosis and cytokine secretion by store-operated calcium entry in primary isolated murine microglia. Cell Signal. 2015;27:177-86.

90. Michaelis M, Nieswandt B, Stegner D, Eilers J, Kraft R. STIM1, STIM2, and Orai1 regulate store-operated calcium entry and purinergic activation of microglia. Glia. 2015;63:652-63.

91. Ohana L, Newell EW, Stanley EF, Schlichter LC. The $\mathrm{Ca}^{2+}$ release-activated $\mathrm{Ca}^{2+}$ current $\left(\mathrm{I}_{\text {CRAC }}\right)$ mediates store-operated $\mathrm{Ca}^{2+}$ entry in rat microglia. Channels. 2009;3:129-39.

92. Siddiqui TA, Lively S, Vincent C, Schlichter LC. Regulation of podosome formation, microglial migration and invasion by $\mathrm{Ca}^{2+}$-signaling molecules expressed in podosomes. J Neuroinflammation. 2012;9:250.

93. Hoffmann A, Kann O, Ohlemeyer C, Hanisch UK, Kettenmann H. Elevation of basal intracellular calcium as a central element in the activation of brain macrophages (microglia): suppression of receptor-evoked calcium signaling and control of release function. J Neurosci. 2003;23:4410-9.

94. Moore CS, Ase AR, Kinsara A, Rao VT, Michell-Robinson M, Leong SY, Butovsky O, Ludwin SK, Seguela P, Bar-Or A, Antel JP. P2Y12 expression and function in alternatively activated human microglia. Neurol Neuroimmunol Neuroinflamm. 2015;2, e80.

95. Neher JJ, Neniskyte U, Brown GC. Primary phagocytosis of neurons by inflamed microglia: potential roles in neurodegeneration. Front Pharmacol. 2012;3:27.

96. Maekawa M, Terasaka S, Mochizuki Y, Kawai K, Ikeda Y, Araki N, Skolnik EY, Taguchi T, Arai H. Sequential breakdown of 3-phosphorylated phosphoinositides is essential for the completion of macropinocytosis. Proc Natl Acad Sci U S A. 2014;111:E978-987.

97. Levin R, Grinstein S, Schlam D. Phosphoinositides in phagocytosis and macropinocytosis. Biochim Biophys Acta. 2015;1851:805-23.

98. Srivastava S, Li Z, Lin L, Liu G, Ko K, Coetzee WA, Skolnik EY. The phosphatidylinositol 3-phosphate phosphatase myotubularin-related protein 6 (MTMR6) is a negative regulator of the $\mathrm{Ca}^{2+}$-activated $\mathrm{K}^{+}$channel KCa3.1. Mol Cell Biol. 2005;25:3630-8.

99. Hsu HY, Chiu SL, Wen MH, Chen KY, Hua KF. Ligands of macrophage scavenger receptor induce cytokine expression via differential modulation of protein kinase signaling pathways. J Biol Chem. 2001;276:28719-30.

100. Todt JC, Hu B, Curtis JL. The scavenger receptor SR-A I/II (CD204) signals via the receptor tyrosine kinase Mertk during apoptotic cell uptake by murine macrophages. J Leukoc Biol. 2008;84:510-8.

101. Hibino H, Inanobe A, Furutani K, Murakami S, Findlay I, Kurachi Y. Inwardly rectifying potassium channels: their structure, function, and physiological roles. Physiol Rev. 2010;90:291-366. 